\title{
Runx1 Controls Terminal Morphology and Mechanosensitivity of VGLUT3-expressing C-Mechanoreceptors
}

\author{
Shan Lou, ${ }^{1 *}$ Bo Duan, ${ }^{1 *}$ Linh Vong, ${ }^{2}$ Bradford B. Lowell, ${ }^{2}$ and Qiufu $\mathrm{Ma}^{1}$ \\ ${ }^{1}$ Dana-Farber Cancer Institute and Department of Neurobiology, Harvard Medical School, Boston, Massachusetts 02115, and ${ }^{2}$ Division of Endocrinology, \\ Department of Medicine, Beth Israel Deaconess Medical Center and Harvard Medical School, Boston, Massachusetts 02215
}

VGLUT3-expressing unmyelinated low-threshold mechanoreceptors (C-LTMRs) are proposed to mediate pleasant touch and/or pain, but the molecular programs controlling C-LTMR development are unknown. Here, we performed genetic fate mapping, showing that VGLUT3 lineage sensory neurons are divided into two groups, based on transient or persistent VGLUT3 expression. VGLUT3-transient neurons are large- or medium-diameter myelinated mechanoreceptors that form the Merkel cell-neurite complex. VGLUT3-persistent neurons are small-diameter unmyelinated neurons that are further divided into two subtypes: (1) tyrosine hydroxylase (TH)-positive C-LTMRs that form the longitudinal lanceolate endings around hairs, and (2) TH-negative neurons that form epidermal-free nerve endings. We then found that VGLUT3-persistent neurons express the runt domain transcription factor Runx1. Analyses of mice with a conditional knock-out of Runx1 in VGLUT3 lineage neurons demonstrate that Runx1 is pivotal to the development of VGLUT3-persistent neurons, such as the expression of VGLUT3 and TH and the formation of the longitudinal lanceolate endings. Furthermore, Runx1 is required to establish mechanosensitivity in C-LTMRs, by controlling the expression of the mechanically gated ion channel Piezo2. Surprisingly, both acute and chronic mechanical pain was largely unaffected in these Runx1 mutants. These findings appear to argue against the recently proposed role of VGLUT3 in C-LTMRs in mediating mechanical hypersensitivity induced by nerve injury or inflammation. Thus, our studies provide new insight into the genetic program controlling C-LTMR development and call for a revisit for the physiological functions of C-LTMRs.

\section{Introduction}

Unmyelinated low threshold mechanoreceptors (C-LTMRs) were first discovered by Zotterman (1939) in cats over 70 years ago, and were subsequently found in all tested mammals, including humans (Björnsdotter et al., 2010; Olausson et al., 2010). Zotterman initially proposed that C-LTMRs might be involved with ticklish sensation (Zotterman, 1939). More recent studies in humans suggested that C-LTMRs signal pleasant touch associated with affiliative social body contact (Löken et al., 2009; Björnsdotter et al., 2010; Olausson et al., 2010). In mice, C-LTMRs in

Received Aug. 17, 2012; revised Nov. 3, 2012; accepted Nov. 8, 2012.

Author contributions: S.L., B.D., and Q.M. designed research; S.L. and B.D. performed research; L.V. and B.L. contributed unpublished reagents/analytic tools; S.L., B.D., and Q.M. analyzed data; S.L., B.D., and Q.M. wrote the paper.

Work done in the Ma laboratory was supported by NIH grants from NIDCR (R01 DE018025) and NINDS (P01 NS047572), and work done in the Lowell laboratory was supported by the NIH grant from NIDDK (R01 DK075632). L. L. was supported by Boston Nutrition Obesity Research Center Pilot and Feasibility (P30 DK046200). We thank Dr. Nancy Speck and Dr. Gary Gilliland for the floxed Runx 1 mice, Dr. David Corey for allowing us to use the recording setup in his laboratory, and Drs. Jing Hu and David Corey for advice on recording mechanically evoked currents on cultured DRG neurons. We thank Drs. Clifford Woolf, Oliver Holmes, and Fu-Chia Yang for helpful discussions and comments.

*S.L. and B.D. contributed equally to this study.

Correspondence should be addressed to Qiufu Ma, Dana-Farber Cancer Institute and Department of Neurobiology, Harvard Medical School, 1 Jimmy Fund Way, Boston, Massachusetts 02115. E-mail: Qiufu_Ma@dfci.harvard.edu.

DOI:10.1523/JNEUROSCI.3942-12.2013

Copyright $\odot 2013$ the authors $\quad 0270-6474 / 13 / 330870-13 \$ 15.00 / 0$ the dorsal root ganglia (DRGs) are marked by the expression of VGLUT3, a vesicular glutamate transporter (Seal et al., 2009), and by the expression of the tyrosine hydroxylase (TH) (Li et al., 2011). The $\mathrm{TH}^{+}$subset of C-LTMRs form longitudinal lanceolate endings around hairs (Li et al., 2011). Mice lacking VGLUT3 showed marked deficits in mechanical allodynia (pain evoked by innocuous mechanical stimuli) induced by inflammation, tissue injury, chemicals (capsaicin), and nerve injury (Seal et al., 2009). Based on these behavioral phenotypes, C-LTMRs were proposed to mediate mechanical pain under pathological conditions (Seal et al., 2009). However, this interpretation is complicated by VGLUT3 expression in many parts of the nervous system in addition to C-LTMRs (Fremeau et al., 2004; El Mestikawy et al., 2011).

In recent years, a number of transcription factors have been identified that control the development of myelinated low threshold mechanoreceptors, including the formation of specialized mechanoreceptor nerve endings and end organs (Arber et al., 2000; Inoue et al., 2002; Kucera et al., 2002; Levanon et al., 2002; Sedý et al., 2006; Senzaki et al., 2010; Abdo et al., 2011; Scott et al., 2011; Wende et al., 2012). However, the genetic program controlling C-LTMR development is entirely unknown. The runt domain transcription factor Runx1 is known to play a pivotal role in controlling the development of a diverse array of unmyelinated sensory neurons, such as pain-related nociceptors, itch-related pruriceptors, and thermoceptors (Liu and Ma, 2011; Lallemend 
and Ernfors, 2012). Runx1 is initially expressed in most embryonic neurons marked by the expression of the nerve growth factor receptor TrkA (Levanon et al., 2002; Theriault et al., 2005; Chen et al., 2006; Kramer et al., 2006; Marmigère et al., 2006; Yoshikawa et al., 2007). In adult mice, persistent Runxl expression is confined to those sensory neurons that have switched off TrkA and activated the expression of the Ret receptor tyrosine kinase (Chen et al., 2006; Kramer et al., 2006). Since C-LTMRs belong to the unmyelinated sensory neuron population, we hypothesized that the development of C-LTMRs is also Runx1 dependent. Here, we demonstrate that Runx1 indeed coordinates C-LTMR development. Furthermore, by creating mice with selective defects in C-LTMRs, we were able to reassess the physiological functions of C-LTMRs.

\section{Materials and Methods}

Animals. The generation of mice carrying the floxed Runx 1 allele and ROSA26-CAG-LSTOPL-tdTomato reporter mice have been described previously (Growney et al., 2005; Madisen et al., 2010). The generation of Vglut3-Cre mice is described elsewhere by L. Vong and B. Lowell, unpublished observations. Both males and females were used. For histochemical studies, 2-3 pairs of control and mutant mice of 1-2 month old were used. For each behavioral analysis, 6-10 pairs of two-month-old mutant and control littermates were used. Animals were assigned in treatment groups in a blinded fashion and pain response was measured in a blinded manner. All behavioral test protocols were approved by the Institutional Animal Care and Use Committee at Dana-Farber Cancer Institute.

In situ hybridization and immunohistochemistry. In situ hybridization procedures (ISH) have been described previously (Chen et al., 2006; Liu et al., 2010). Antisense Piezo2 probe ( $928 \mathrm{bp}$ ), VGLUT3 probe (764 bp), and $\mathrm{TH}$ probe (952 bp) were amplified from cDNA prepared from adult DRGs, and labeled with digoxigenin (Roche Diagnostics). Immunohistochemistry on DRG sections was performed using rabbit anti-NF200 (1/500, Millipore), diluted in $0.1 \%$ of Triton X-100 plus $10 \%$ of goat serum in PBS. The ISH/Tomato double staining was performed as previously described (Liu et al., 2010); the Tomato fluorescent signal was first photographed, followed by ISH. The pseudo fluorescent ISH signals (for VGLUT3, TH, and Piezo2) were converted from bright field images and then merged onto the Tomato images. For skin Tomato/immunohistochemistry (IHC) double staining, rabbit anti-NF200 (1/500, Millipore), rabbit anti-VGLUT3 (1/100, Sys), mouse anti CK20 (1/20, Abcam), and rabbit anti-S100 (1/400, Dako) were used. Different parts of skin (glabrous hindpaw and hairy back skin) were dissected in Zamboni's fixation solution, cryoprotected, and embedded in OCT compound. Frozen sections ( $30 \mu \mathrm{m}$ thick) were cut, washed with PBS, and made into floating sections. The floating sections were washed with PBS, blocked with $10 \%$ goat serum, and incubated with various antibodies overnight at $4^{\circ} \mathrm{C}$. Following incubation with the primary antibodies, sections were washed and incubated with the appropriate secondary antibodies.

Cell and innervation quantification. Lumbar DRGs from mutant and control mice were dissected. For each marker, 3-6 pairs of mutant and control DRGs from different mice were used and six adjacent sections at $14 \mu \mathrm{m}$ thickness were prepared from each DRG. Each set was processed for immunostaining or used for ISH with the marker of interest, and positive cells with nuclei were counted. For the innervation quantification, $1.5 \times 1.5 \mathrm{~cm}^{2}$ back skin from three mutant and five control mice were collected. Back skins were fixed in 4\% PFA, cryoprotected in $20 \%$ sucrose, embedded in OCT, and cut into $30-\mu \mathrm{m}$-thick sections. Approximately 50 visual fields from $20 \times$ Zeiss fluorescence microscope were randomly chosen from each animal, and the number of hair follicles in the visual field, the number of hair follicles that are innervated by fluorescent fibers, and the number of fluorescent fibers that are clearly longitudinal or circumferential lanceolate endings were documented for statistics analyses.

$D R G$ neuron culture and RNAi. Mice at P14-P16 were killed by $\mathrm{CO}_{2}$ inhalation and DRGs from T10-L6 were collected in $\mathrm{Ca}^{2+}$ and $\mathrm{Mg}^{2+}$ - free HBSS. DRGs were subsequently treated with papain $(1.5 \mathrm{mg} / \mathrm{ml}$, Roche) and collagenase/dispase (1 mg/ml, Roche) for 15 and $20 \mathrm{~min}$, respectively, at $37^{\circ} \mathrm{C}$. Digested DRGs were washed twice with growth medium (DMEM-F12, Invitrogen) supplemented with GlutaMAX (Invitrogen) and $10 \%$ fetal bovine serum (HyClone), triturated using firepolished Pasteur pipettes, and plated in a droplet of growth medium on a glass coverslip precoated with poly-D-lysine $(20 \mu \mathrm{g} / \mathrm{ml}$, Sigma $)$ and laminin $(20 \mu \mathrm{g} / \mathrm{ml}$, Sigma). To allow neurons to adhere, coverslips were kept for $2 \mathrm{~h}$ at $37^{\circ} \mathrm{C}$ in a humidified $5 \%$ incubator before being flooded with fresh growth medium. To increase the survival of DRG neurons, recombinant human GDNF ( $2 \mathrm{ng} / \mathrm{ml}$, R\&D Systems) was added in the growth medium. Cultures were used for patch-clamp experiments on the next day.

Small interference RNA-mediated knockdown of Piezo2 was achieved by electroporation of a pool of four different siRNA (250 nM totally) purchased from Qiagen (target sequences: GAATGTAATTGGACAGCG A, TCATGAAGGTGCTGGGTAA, GATTATCCATGGAGATTTA, GA AGAAAGGCATGAGGTAA) into freshly dissociated DRG neurons using the nucleofector kit with the nucleofector type II device (DRG, O-003 program; Lonza) based on the previous study (Coste et al., 2010). A scrambled siRNA ( $250 \mathrm{~nm}$, Qiagen) was transfected as control. To test the efficiency of electroporation, a 3'-Alexa Fluor 488-conjugated scramble siRNA (5 nм, Qiagen) was co-transfected. Further patch-clamp experiments were performed at $48-72 \mathrm{~h}$ after electroporation.

Electrophysiology. The electrophysiological recordings were performed in the conventional whole-cell patch recording configuration under voltage-clamp condition. Membrane currents were measured using Axoclamp 200B with Digidata 1320A and the pClamp 9 software (Molecular Devices). Patch pipettes (3-4 M $\Omega$ ) were filled with the following (in $\mathrm{mm}): 140 \mathrm{KCl}, 1 \mathrm{CaCl}_{2}, 2 \mathrm{MgCl}_{2}, 10$ EGTA, $2 \mathrm{MgATP}$, and 10 HEPES, $\mathrm{pH}$ 7.2. The standard extracellular solution contained the following (in $\mathrm{mm}$ ): $150 \mathrm{NaCl}, 5 \mathrm{KCl}, 1 \mathrm{MgCl}_{2}, 2 \mathrm{CaCl}_{2}, 10$ glucose, and 10 HEPES, pH7.4. The membrane potential was voltage clamped at $-60 \mathrm{mV}$ throughout the experiments under voltage-clamp conditions. All experiments were performed at room temperature $\left(22-25^{\circ} \mathrm{C}\right)$

Mechanical stimulation. For whole-cell recordings, mechanical stimulation was achieved using a fire-polished glass pipette (tip diameter, $\sim 2$ $\mu \mathrm{m})$ positioned at an angle of $40^{\circ}$ to the surface of the dish. Downward movement of the probe toward the cell was driven by a Clampexcontrolled piezoelectric stimulator (Corey and Hudspeth, 1980; Hao and Delmas, 2011). The stimulus was applied for $100 \mathrm{~ms}$. To assess the mechanical sensitivity of a cell, a series of mechanical steps in $2 \mu \mathrm{m}$ increments was applied every $20 \mathrm{~s}$, which allowed full recovery of mechanosensitive currents. For recordings of mechanically evoked currents in DRG neurons, the inactivation kinetics of traces of currents reaching at least $75 \%$ of the maximal amplitude of current elicited per cell were fitted with mono- or bi- (if mono-exponential function cannot fit well) exponential functions (Drew et al., 2004) and classified as rapidly adapting-, mixed adapting-, and slowly adapting-type currents according to their inactivation time constant.

Capsaicin-induced acute pain and secondary hyperalgesia. For the glabrous skin, capsaicin ( $3 \mu \mathrm{g} / 10 \mu \mathrm{l}$, Tocris Bioscience) was injected into the plantar of the hindpaw and the amount of time licking the hindpaw was determined in a 5 min period after injection. To measure secondary hyperalgesia, mechanical thresholds in response to von Frey filaments were determined at regions adjacent to the injection site $0,15,30$, and 60 min after injection.

To examine mechanical hyperalgesia induced by capsaicin in the hairy skin, capsaicin $(3 \mu \mathrm{g} / 5 \mu \mathrm{l})$ was injected into the central site of the dorsal hindpaw and mechanical thresholds in response to von Frey filaments were determined at regions adjacent to the injection site.

Neuropathic pain (spared nerve injury). Unilateral spared nerve injury was done by exposing the sciatic nerve in the thigh region of the adult mouse ( 2 months), cutting and ligating the tibial and common peroneal nerves, and leaving the remaining sural nerve intact (Decosterd and Woolf, 2000). Animals were subjected to testing at 3-15 d after lesion, in the plantar region of the left hind foot that was innervated by the sural nerve. 
Inflammatory pain. We injected $20 \mu \mathrm{l}$ of carrageenan (1\%, Sigma) or complete Freund's adjuvant (CFA, Sigma) into the plantar surface of the hindpaw to induce inflammatory pain. Both mechanical threshold and radiant heat sensitivity were measured $2-24 \mathrm{~h}$ after carrageenan treatment and $3 \mathrm{~d}$ after CFA treatment, respectively.

Pain behavioral test. All animals were acclimatized to the behavioral testing apparatus on three to five "habituation" sessions. After habituation, baseline measures were recorded on two consecutive days for each of the behavioral tests before the surgery or chemical injection. After surgical procedures or chemical compound injections, the behavioral tests were performed at defined intervals (see Fig. 7). The experimenter was blinded to the genotype of the animals. For tests using the RandallSelitto device (IITC), mice were placed in a restraining plastic tube and allowed $5 \mathrm{~min}$ to acclimatize. Slowly ascending pressure was then applied to a point midway along the tail until the animal showed a clear sign of discomfort or tried to escape, and this pressure was taken as the pain threshold. For the von Frey test, we placed the animals on an elevated wire grid and the lateral plantar surface of the hindpaw was stimulated with calibrated von Frey monofilaments $(0.008-1.4 \mathrm{~g})$. The $50 \%$ paw withdrawal threshold for the von Frey assay was determined using Dixon's up-down method (Chaplan et al., 1994). To measure radiant heat pain, animals were put in plastic boxes and the plantar paw surface was exposed to a beam of radiant heat (IITC) according to the Hargreaves method (Hargreaves et al., 1988). Paw withdrawal latency was then recorded (beam intensity was adjusted to result in a latency of $8-12 \mathrm{~s}$ for control animals baselines). The heat stimulation was repeated five times at an interval of $10 \mathrm{~min}$ for each animal and the mean calculated. A cutoff time of $30 \mathrm{~s}$ was set to prevent tissue damage.

Statistics. Results are expressed as \pm SEM. For acute pain, capsaicininduced licking behavior and CFA-induced inflammatory pain, data were subjected to the Student's $t$ test. For capsaicin-induced secondary hyperalgesia, carrageenan-induced inflammatory and spared nerve injury (SNI)-induced neuropathic pain, time course measurements were analyzed by both ANOVAs between groups, with $p<0.05$ accepted as statistically significant.

\section{Results}

\section{Genetic marking of VGLUT3 lineage sensory neurons}

To mark VGLUT3 lineage DRG neurons, we crossed Vglut3-Cre mice, in which an IRES-Cre cassette was inserted into the $3^{\prime}$ end of the Vglut3 locus, with ROSA26-CAG-LSL-tdTomato reporter mice (Madisen et al., 2010), with the resulting double heterozygous mice referred to as $\mathrm{ROSA} \mathrm{Tomato} /+^{+} ; \mathrm{Vglut} 3^{\mathrm{Cre} /+}$ mice (Fig. $1 \mathrm{~A})$. In $\mathrm{ROSA}^{\text {Tomato/+ }} ; \mathrm{Vglut}^{\mathrm{Cre} /+}$ mice, VGLUT3 lineage neurons are permanently marked by red fluorescent Tomato expression, regardless of persistent or transient VGLUT3 expression. We found that $18.9 \%$ (674/3574) of adult lumbar DRG neurons, visualized with the expression of the pan neuronal marker SCG10, were Tomato-positive (data not shown). All neurons with detectable VGLUT3 mRNA coexpressed Tomato (Fig. $1 B$ ), suggesting that VGLUT3-Cre faithfully marks VGLUT3expressing $\left(\right.$ VGLUT3 $^{+}$) sensory neurons in the DRG. However, we did note that only $85.4 \%$ of Tomato ${ }^{+}$neurons showed detectable VGLUT3 mRNA (Fig. $1 B$, arrow). VGLUT3-positive Tomato ${ }^{+}$neurons belong predominantly to small-diameter DRG neurons (Fig. $1 \mathrm{~B}$, arrow), whereas the remaining $14.6 \%$ of VGLUT3-negative Tomato ${ }^{+}$neurons represent medium- (Fig. $1 \mathrm{~B}$, arrowhead) or large- (Fig. $1 \mathrm{~B}$, dashed circle) diameter neurons. At P0.5, some large neurons did show detectable VGLUT3 expression (Fig. 1C, dashed circle), indicating that adult VGLUT3-negative Tomato $^{+}$neurons represent neurons with transient VGLUT3 expression. It should also be noted that at P0.5, Tomato expression had not yet been established in some neurons with detectable VGLUT3 mRNA (Fig. 1C, arrowhead), suggesting that VGLUT3 expression was initiated at prenatal or neonatal stages. Thus, adult $\mathrm{Tomato}^{+}$neurons are divided into two groups: small VGLUT3-persistent versus large/medium VGLUT3-transient.

VGLUT3-persistent neurons are unmyelinated (Seal et al., 2009). Consistently, NF200, a marker for myelinated DRG neurons, was not expressed in small Tomato ${ }^{+}$neurons (Fig. $1 D$, arrows). In contrast, NF200 expression was detected in medium/large Tomato ${ }^{+}$neurons (Fig. $1 D$, arrowheads and dashed circles). Thus, VGLUT3-persistent and VGLUT3-transient Tomato ${ }^{+}$neurons represent unmyelinated and myelinated neurons, respectively.

A subset of VGLUT3-persistent neurons can also be marked by the expression of $\mathrm{TH}$, and electrophysiological recording shows that they represent C-LTMRs (Seal et al., 2009; Li et al., 2011). We found that in adult lumbar DRG of ROSA ${ }^{\text {Tomato/+'}}$;

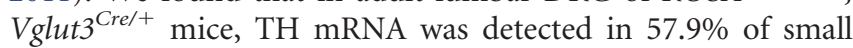
diameter Tomato $^{+}$neurons (Fig. $1 E$, arrow). Thus, VGLUT3persistent neurons (representing $85.4 \%$ of total Tomato ${ }^{+}$neurons) are divided into $\mathrm{TH}^{+} \mathrm{C}$-LTMRs $(\sim 58 \%)$ and TH-negative $\left(\mathrm{TH}^{-}\right)$neurons $(\sim 27 \%)$.

Thus, the genetic fate mapping experiments reveal four subsets of VGLUT3 lineage neurons in DRG (Fig. $1 F$ ): medium- and large-diameter subsets of VGLUT3-transient myelinated A-mechanoreceptors (for mechanosensitivity, see below), $\mathrm{TH}^{+}$VGLUT3-persistent C-LTMRs, and $\mathrm{TH}^{-}$ VGLUT3-persistent neurons.

\section{Skin innervations by VGLUT3 lineage sensory neurons}

To examine peripheral innervations, we took advantage of ROSA $^{\text {Tomato/+ }} ; \mathrm{Vglut}^{\mathrm{Cre} /+}$ mice, in which Tomato expression can be used to directly visualize axonal endings. From transverse sections through hairy back skin, we sampled 266 hair follicles from five different mice and found that Tomato ${ }^{+}$fibers innervated $64.2 \%$ (171/266) of these hair follicles (Fig. $2 A$, arrow). The actual percentage of hairs with Tomato ${ }^{+}$fibers is likely higher since transverse sections may cut through parts of the hairs that do not contain Tomato $^{+}$fibers. Most of these Tomato ${ }^{+}$fibers form longitudinal lanceolate endings (Fig. $2 A, B$ ). A double staining with NF200, a marker for myelinated fibers, showed that these Tomato $^{+}$lanceolate endings were NF200-negative (Fig. 2A,B, arrows), and were wrapped with NF200 ${ }^{+}$circumferential endings (Fig. $2 \mathrm{~A}$, arrowheads) and in some cases intertwined with NF200 ${ }^{+}$longitudinal lanceolate endings (Fig. 2 B, arrowheads). These unmyelinated Tomato ${ }^{+}$lanceolate endings are most likely derived from the $\mathrm{TH}^{+}$subset of VGLUT3-persistent C-LTMRs, as reported previously (Li et al., 2011).

We also observed two other types of unmyelinated Tomato ${ }^{+}$ nerve endings. In the hairy skin, NF200 ${ }^{-}$(thereby unmyelinated) Tomato ${ }^{+}$-free nerve endings were observed in the epidermis adjacent to hair follicles (Fig. $2 C$, arrow). In the glabrous skin, we observed another type of Tomato $^{+}$epidermal-free nerve (Fig. $2 D$, arrow). These fibers entered the epidermis through the dermal papillae and extended all the way to the stratum corneum (or the cornified layer) of skin (Fig. 2D). Within the dermal papillae, Tomato $^{+}$fibers were continuous and sometimes intertwined with NF200 ${ }^{+}$Meissner's corpuscles (Fig. 2D, arrowhead). However, in the outer layers of the epidermis, we observed strings of varicosities (Fig. 2D, arrow). The resolution of our microscope failed to distinguish whether these varicosities were linked with nerve segments, or represented fibers dying back from the cornified layer. We referred to these previously un-described nerve fibers as "Dermal Papillae-Epidermis" or "D.P.E." nerve endings. Because $\mathrm{TH}^{+}$C-LTMRs only innervate hairs (Li et al., 2011), 
A

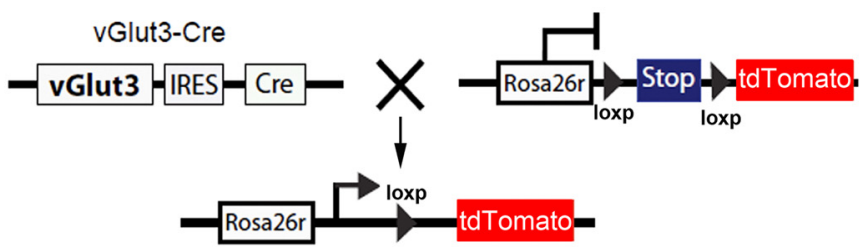

B
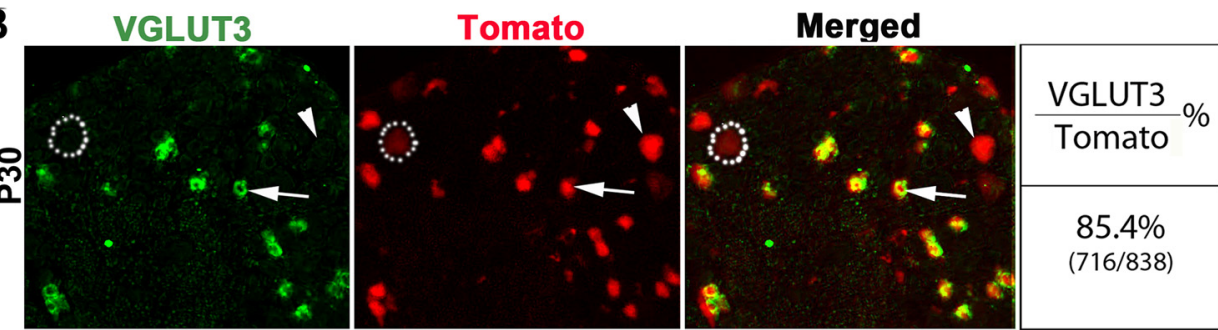

C

VGLUT3

Tomato

Merged
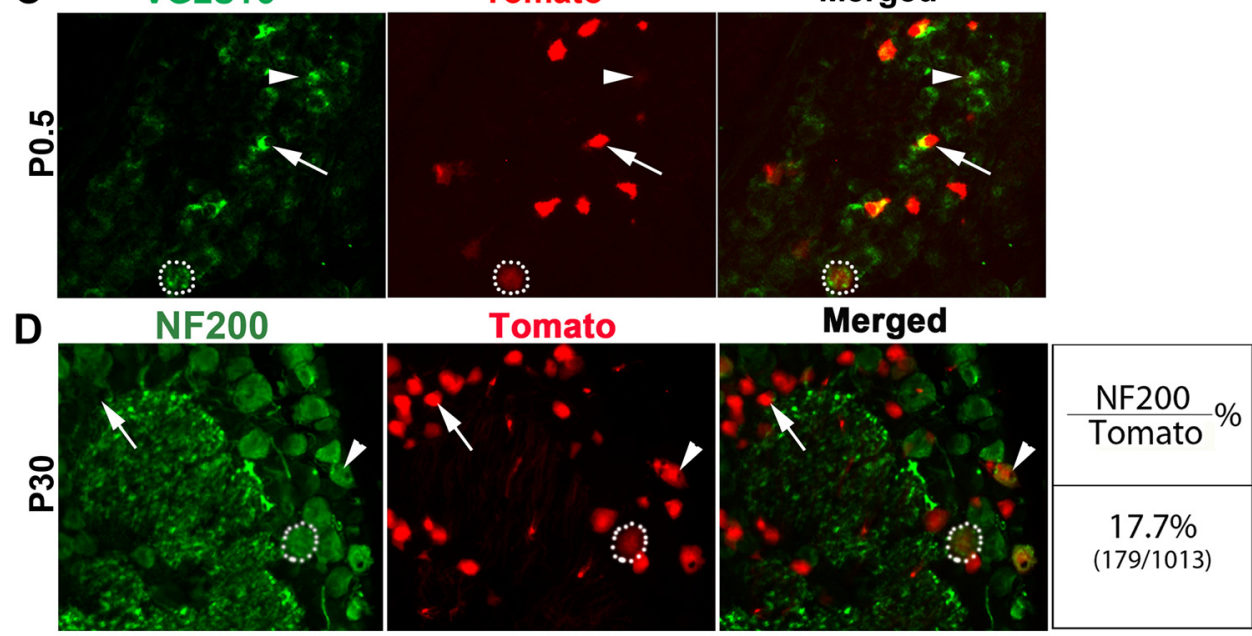

$\mathbf{E}$
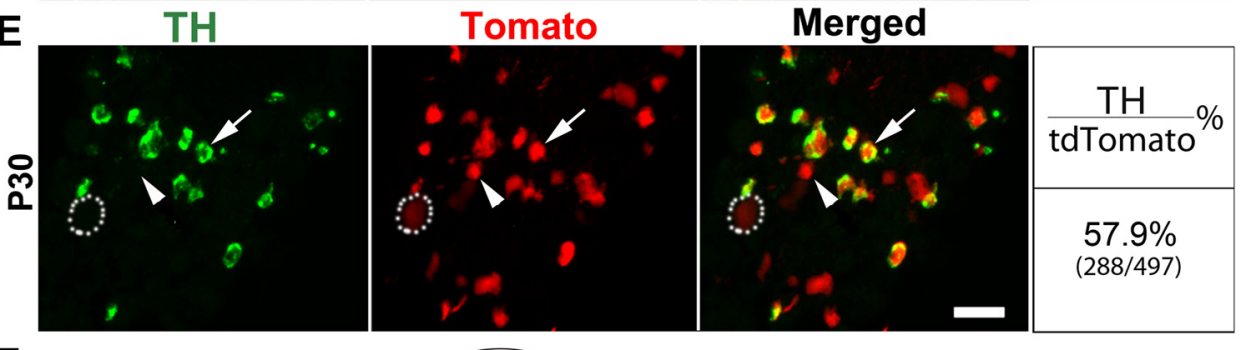

$\mathbf{F}$

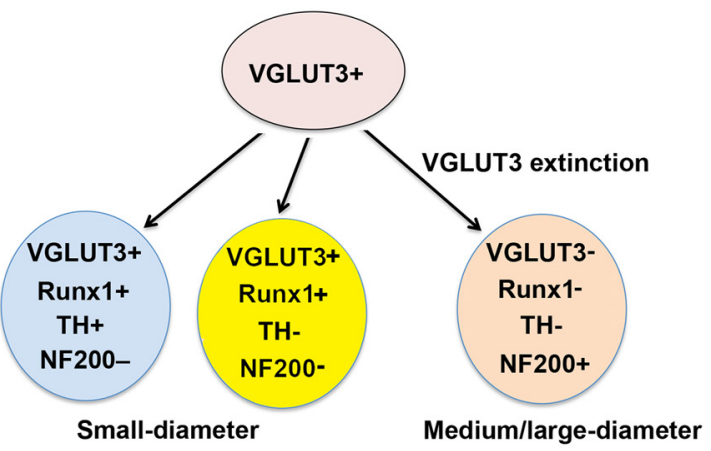

Figure 1. Genetic marking of VGLUT3 lineage sensory neurons. $A$, Scheme of making ROSA $A^{\text {Tomato/ }}$; Vglut $3^{\text {Cre/+ }}$ mice. $\boldsymbol{B}-\boldsymbol{E}$, Double staining of Tomato with VGLUT3 mRNA, NF200 protein, or TH mRNA on sections through lumbar DRG of ROSA ${ }^{\text {Tomato/+ }}$; $V$ glut $^{3 \text { re/+ }}{ }^{+}$mice at indicated ages. $\boldsymbol{B}, \mathbf{D}, \boldsymbol{E}$, Arrow, arrowhead, and dashed circle indicate the small-, medium-, and large-diameter Tomato ${ }^{+}$neurons, respectively. C, Arrow and dashed circle indicating small and large Tomato ${ }^{+}$neurons, respectively, with detectable VGLUT3 mRNA. Arrowhead indicating a neuron with detectable VGLUT3 mRNA, but having not yet turned on Tomato. $\boldsymbol{E}$, Arrow and arrowhead indicating TH-positive and TH-negative small Tomato ${ }^{+}$cells, respectively. Dashed circles indicate large TH-negative Tomato ${ }^{+}$neurons. $\boldsymbol{F}$, Summary of distinct molecular identities of VGLUT3-persistent versus VGLUT3-transient DRG neurons, based on data shown here and Figure 3. Scale bars, $50 \mu \mathrm{m}$. 
these unmyelinated epidermal nerve endings are most likely derived from the $\mathrm{TH}^{-}$ subset of VGLUT3-persistent neurons.

VGLUT3-transient A-mechanoreceptors appear to form Merkel-cell neurite complex. First of all, VGLUT3 itself was expressed in Merkel cells, as indicated by the coexpression of Tomato with the Merkel cell marker CK20 in the touch dome of the hairy skin (Fig. 2E, arrowheads). This VGLUT3 expression was further confirmed by immunostaining (see below) and is consistent with previous reports (Haeberle et al., 2004; Nunzi et al., 2004). Whole-mount preparation of the hairy skin from $\mathrm{ROSA}^{\text {Tomato/+ }}$; Vglut $3^{\mathrm{Cre} /+}$ mice revealed Tomato ${ }^{+}$fibers innervating the touch domes (Fig. 2E, arrow). These Tomato ${ }^{+}$fibers were myelinated, as suggested by the association of $\mathrm{S} 00^{+}$Schwann cells (Fig. 2F, arrow) and by the coexpression of NF200 (data not shown). Thus, these myelinated Tomato $^{+}$fibers are most likely derived from medium/large VGLUT3transient A-mechanoreceptors.

To conclude this section of the results, each type of VGLUT3 lineage neurons has its specific terminal morphology (summarized in Fig. 2G). $\mathrm{TH}^{+}$VGLUT3-persistent C-LTMRs form longitudinal lanceolate endings around hairs. $\mathrm{TH}^{-}$VGLUT3persistent neurons form epidermal-free nerve endings adjacent to hairs or the D.P.E. ending passing through the dermal papillae in the thick glabrous skin. VGLUT3transient A-mechanoreceptors form the Merkel cell-neurite complex.

\section{Runx1 controls VGLUT3 and TH expression in C-LTMRs}

We next asked how C-LTMRs are specified during development. Runx1 is a transcriptional factor that coordinates the development of a large cohort of unmyelinated DRG neurons (Liu and Ma, 2011). We found that Runxl mRNA was detected in most, if not all, small-diameter Tomato ${ }^{+}$neurons in lumbar DRG of adult $R O S A^{\text {Tomato/+ }}$; Vglut $3^{\text {Cre/+ }}$ mice (Fig. $3 A$, arrows). In contrast, Runx1 expression was not detected in medium/ large Tomato $^{+}$neurons (Fig. 3A, arrowheads and dashed circles). In other words, Runx1 is associated exclusively with C-LTMRs within VGLUT3 lineage DRG neurons (summarized in Fig. $1 F$ ).

To determine the role of Runx1 in controlling C-LTMR development, we crossed $\mathrm{Vglut} 3^{\mathrm{Cre} /+}$ mice with mice carrying a floxed allele of Runxl (Runx $\left.1^{F /+}\right)$ (Growney et al., 2005), with the resulting conditional null mice referred to as Run $x 1^{F / F} ;$ Vglut $^{C r e /+}$. In these mutants,
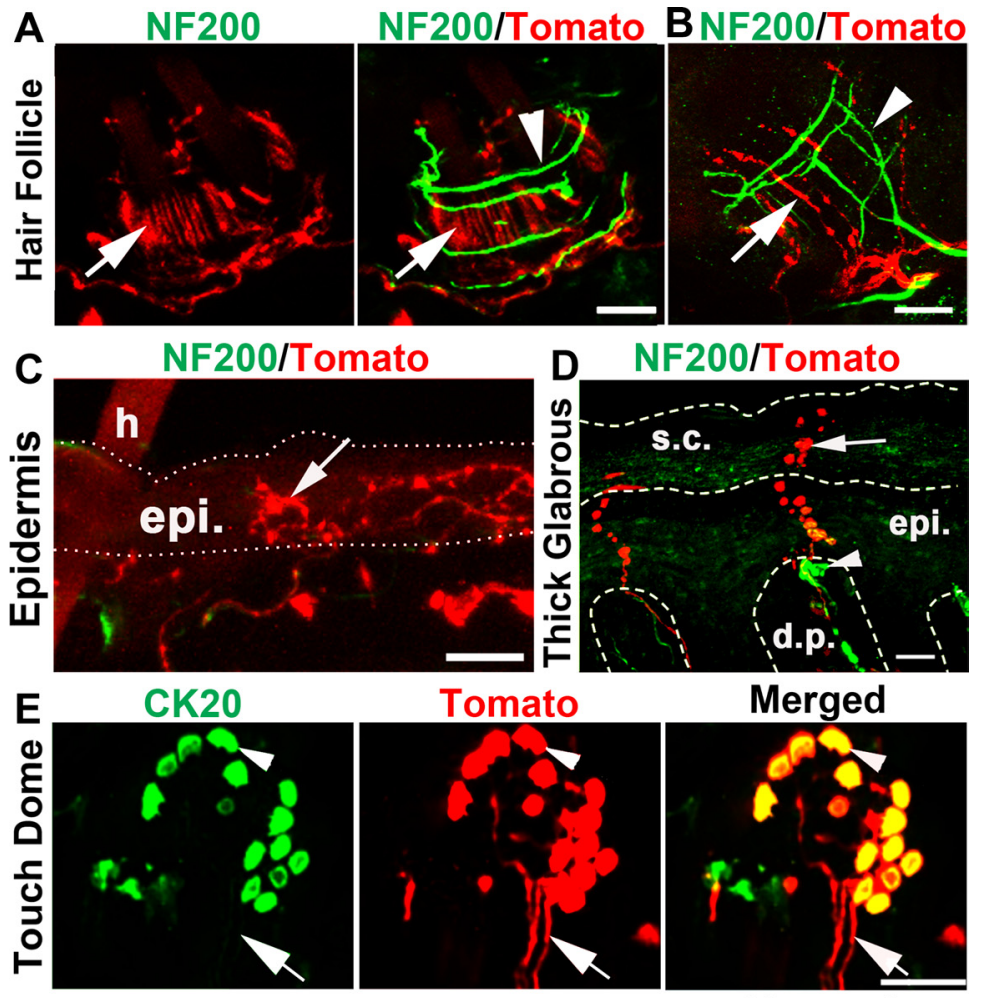

Tomato
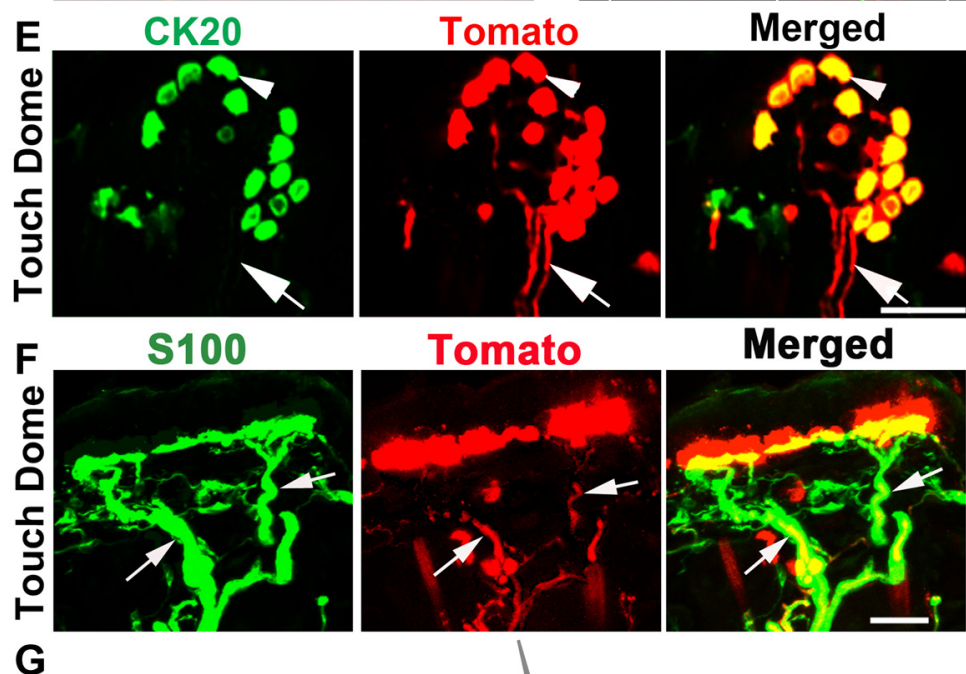

Merged
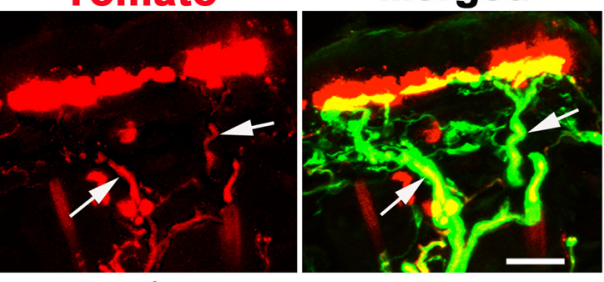

G

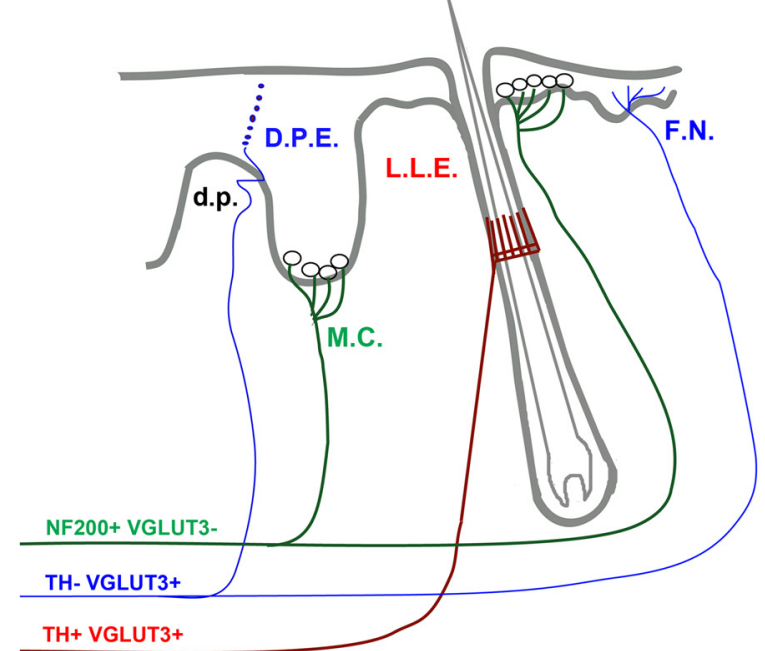

Figure 2. Skin innervations by VGLUT3 lineage sensory neurons. $A-D$, Double staining of Tomato with NF200 on sections through the hairy skin (A-C) or the glabrous skin (D). $A, B$, Arrow indicating Tomato ${ }^{+} ; \mathrm{NF200^{- }}$ longitudinal lanceolate endings wrapped by NF $200^{+}$ circumferential ending ( $\boldsymbol{A}$, arrowhead) or intertwined with NF200 ${ }^{+}$longitudinal lanceolate endings ( $\boldsymbol{B}$, arrowhead). $\boldsymbol{C}$, Arrow indicating $\mathrm{NF} 200^{-}$;Tomato ${ }^{+}$-free nerve endings in the epidermis (epi.) adjacent to a hair (h). D, Arrow indicating a Tomato ${ }^{+}$fiber passing through the dermal papillae (d.p.) and then entering the epidermis (epi.) and the stratum corneum (s.c), referred to as the D.P.E ending (summarized in G). Arrowhead in $\boldsymbol{D}$ indicates a NF200 ${ }^{+}$Meissner's corpuscle. $\boldsymbol{E}$, Whole-mount double staining of Tomato with the Merkel cell

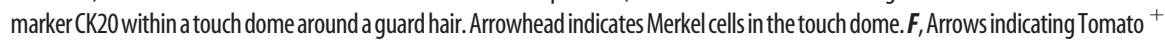
fibers innervating the touch dome of the hairy skin are wrapped by $S 100^{+}$Schwann cells (green). G, Schematic summary of nerve endings from VGLUT3 lineage sensory neurons. F.N., Free nerve endings; L.L.E., Iongitudinal lanceolate endings; M.C., Merkel cell complex. Red and blueindicating fibers derived from $\mathrm{TH}^{+}$and $\mathrm{TH}^{-}$VGLUT3-persistentneurons, respectively; green indicates fibers derived from myelinated VGLUT3-transient mechanoreceptors. Scale bars, $20 \mu \mathrm{m}$. 

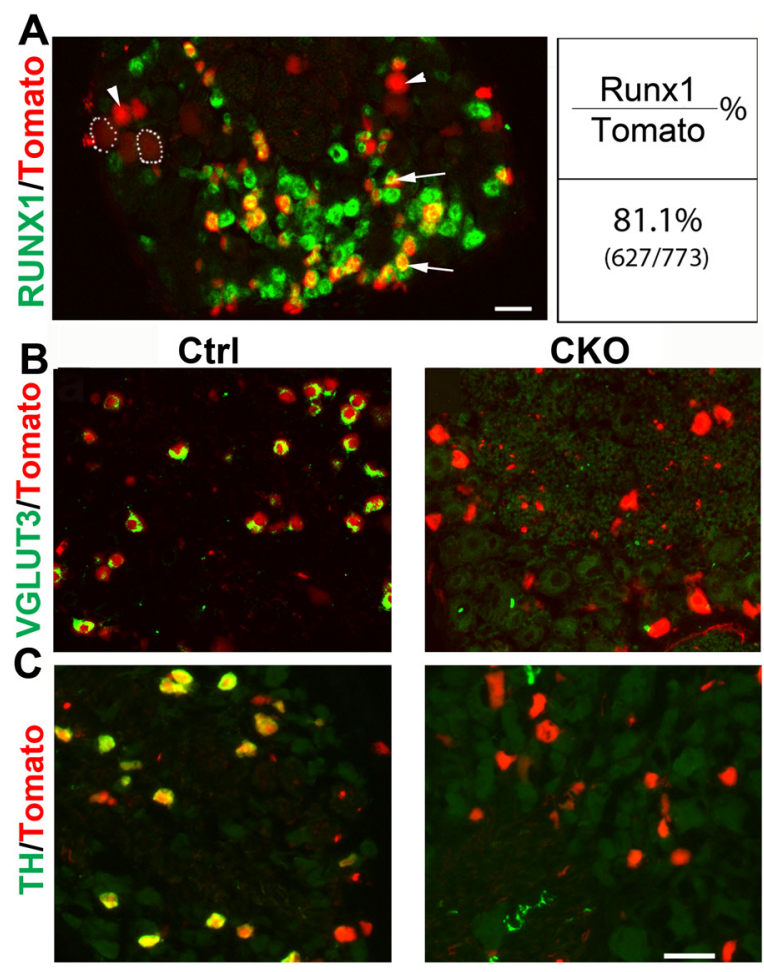
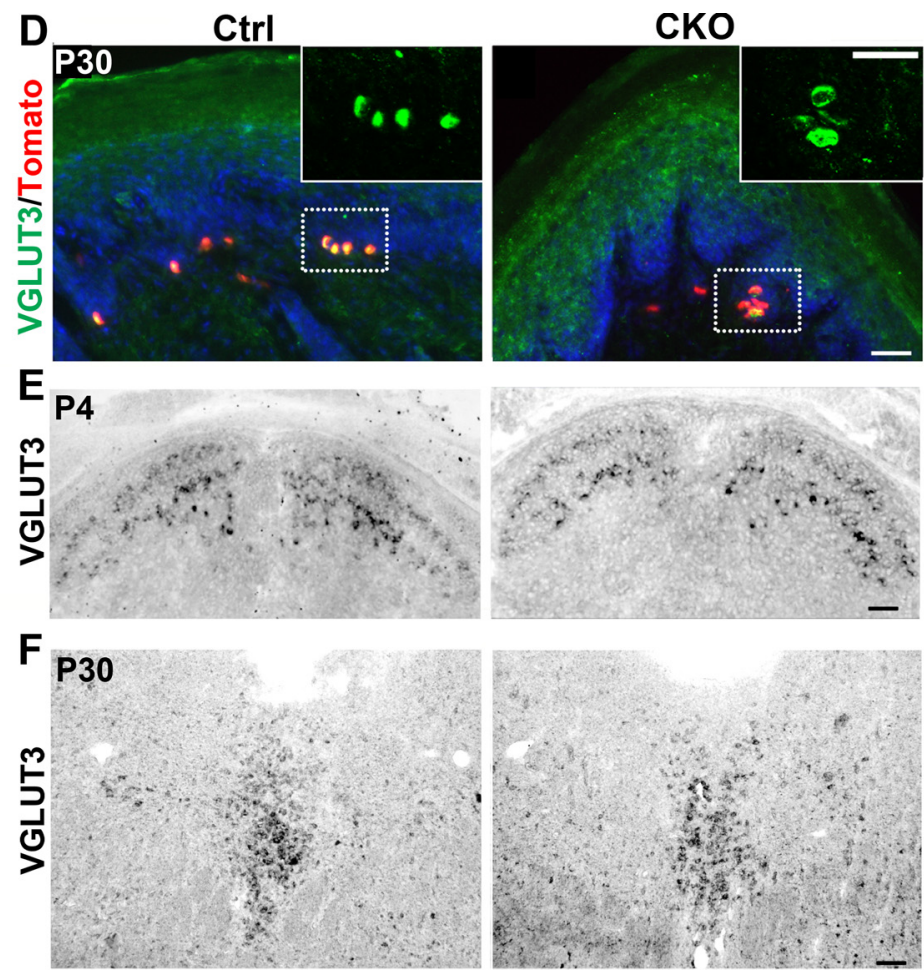

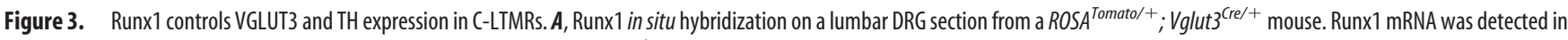
small (arrows), but not medium (arrowheads) or large (dashed circles) Tomato ${ }^{+}$neurons. $\boldsymbol{B}, \boldsymbol{C}$, Double staining of Tomato with VGLUT3 mRNA (B) or TH mRNA (C) detected by in situ hybridization on lumbar DRG sections from the ROSA ${ }^{\text {Tomato/+ }}$; Vglut3 ${ }^{\text {Cre/+ }}$ control mice (Ctrl) or Runx $1^{\text {F/F. }}$;ROSA ${ }^{\text {Tomato/+ }}$; Vglut $3^{\text {Cre/+ }}$ mutant mice (CKO). D, Double staining of Tomato with VGLUT3 immunostaining on sections through the thick glabrous skin from Ctrl and CKO mice. Red indicates Merkel cells, and the inserts are the higher magnification of the dashed boxes. $\boldsymbol{E}, \boldsymbol{F}$, VGLUT3 in situ hybridization on sections through P7 spinal dorsal horn $(\boldsymbol{E})$ or the adult dorsal raphe nuclei of the brainstem $(\boldsymbol{F})$ of the Ctrl and CKO mice. Scale bars, $50 \mu \mathrm{m}$.

Cre-mediated recombination selectively removed Runx1 from VGLUT3 lineage sensory neurons. To monitor VGLUT3 lineage neurons by Tomato expression, we further created mutants carrying the ROSA26-CAG-LSTOPL-tdTomato reporter allele, referred to as $R u n x 1^{F / F} ; R_{O S A}{ }^{\text {Tomato/+}} ; V_{\text {glut }}{ }^{\text {Cre/+ }}$. In situ hybridization showed that VGLUT3 mRNA, detected in adult lumbar DRG from control mice, was not detected in DRGs from Runx $1^{\text {F/F }} ;$ ROSA $^{\text {Tomato/+ }}$; Vglut $3^{\text {Cre/+ }}$ mice (Fig. $3 B$ ). Mutant sensory neurons survived, as indicated by similar percentages of lumbar DRG neurons that were Tomato $^{+}$in mutant mice $(20.8 \%)$ versus control mice $(18.9 \%)$. Because Vglut $3^{\mathrm{Cre} /+}$ mice were used to make Runxl (in other words, Runx1 knock-out occurred after onset of VGLUT3 expression), VGLUT3 expression was observed in some DRG neurons at P4.5, but not after P7 (data not shown). Thus, Runx1 is required to maintain VGLUT3 expression. TH expression was also eliminated (Fig. 3C; data not shown), further indicating an impairment of C-LTMRs in Runx $^{\text {F/F }} ;$ ROSA $^{\text {Tomato/+ }} ;$ Vglut $^{\text {Cre/+ }}$ mice.

Other than DRG neurons, Runx1 expression is rarely detected in the nervous system (Levanon et al., 2002; Zagami and Stifani, 2010). Consistently, we have not yet detected a loss of VGLUT3 expression in other neural cells in Runx1 knock-outs. First, the VGLUT3 protein detected by immunostaining was still present in $\mathrm{CK} 20^{+}$Merkel cells in the thick glabrous skin of Runx1 ${ }^{F / F}$; ROSA $^{\text {Tomato/+ }}$; Vglut $3^{\text {Cre/+ }}$ mice (Fig. 3D). Second, VGLUT3 is expressed transiently in the dorsal spinal cord in wild-type mice, detectable at P4, and downregulated at P56 (Allen mouse spinal cord atlas, http://mousespinal.brain-map.org). We found that at P7, normal VGLUT3 expression was still detected in the dorsal spinal cord of $\mathrm{Runx} \mathrm{I}^{\mathrm{F} / \mathrm{F}} ; \mathrm{ROSA}^{\text {Tomato/+}} ; \mathrm{Vglut}^{\mathrm{Cre} /+}$ mice (Fig. 3E), despite that VGLUT3 expression was already lost in lumbar DRG at this stage (data not shown). Finally, normal VGLUT3 expression was detected in serotonergic neurons in the adult hindbrain raphe nuclei (Fig. $3 F$ ) and in many other parts of the brain (data not shown). Thus, in $\mathrm{Run} \times 1^{\mathrm{F/F}} ; \mathrm{ROSA}^{\text {Tomato/+}} ; \mathrm{Vglut}^{\mathrm{Cre} /+}$ mice, VGLUT3 expression appears to be selectively eliminated in VGLUT3-expressing DRG neurons.

Runx1 controls the formation of C-LTMRs lanceolate endings We next examined how peripheral terminal morphologies of VGLUT3 lineage neurons were affected in $R u n \times 1^{F / F}$; ROSA ${ }^{\text {Tomato/+ }}$; Vglut $3^{\text {Cre/+ }}$ mutant mice, using ROSA $^{\text {Tomato/+ }}$; $\mathrm{Vglut}^{\mathrm{Cre} /+}$ littermates as the control. A whole-mount view on the hairy skin showed that in control mice, most Tomato ${ }^{+}$fibers innervating hair follicles showed clear longitudinal lanceolate endings (Fig. 4A, $B$, left column, arrows). In contrast, while To-

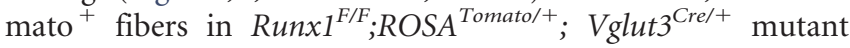
mice still innervated hair follicles, most of them did not form longitudinal lanceolate endings (Fig. $4 A, B$, right column), and instead circumferential Tomato ${ }^{+}$endings were observed (Fig. $4 A, B$, right column, arrowheads). Thus, either the loss of longitudinal lanceolate endings unmasks Tomato $^{+}$circumferential endings, or a transformation from longitudinal to circumferential endings had occurred (Fig. 4C). A double staining with NF200 further showed that these Tomato ${ }^{+}$circumferential endings (Fig. $4 B$, small arrowheads) were located ventral to Tomatonegative NF200 ${ }^{+}$myelinated circumferential endings (Fig. 4B, big arrowheads).

In the epidermis around hairs, no obvious reduction of Tomato $^{+}$-free nerve endings was observed (data not shown). The morphology of the unmyelinated D.P.E endings in the thick glabrous skin was also unchanged (data not shown). Also un- 
changed was the innervation of the touch dome by Tomato $^{+}$myelinated mechanoreceptors (data not shown), consistent with a lack of Runx 1 expression in VGLUT3-transient A-mechanoreceptors. Thus, despite Runx1 controlling VGLUT3 expression in both $\mathrm{TH}^{+}$and $\mathrm{TH}^{-}$neurons, Runxl is required selectively for $\mathrm{TH}^{+}$C-LTMRs to form unmyelinated lanceolate endings.

\section{Runx1 controls mechanosensitivity in VGLUT3 $^{+}$neurons}

To examine mechanosensitivity, we performed whole-cell patch recordings on cultured DRG neurons (McCarter et al., 1999; Drew et al., 2002; Hu and Lewin, 2006; Coste et al., 2010; Vilceanu and Stucky, 2010). We first tried $R O S A^{T o}$. mato/+; Vglut $3^{\mathrm{Cre} /+}$ control mice, by applying mechanical forces to the cell surface of Tomato ${ }^{+}$neurons (visualized under a fluorescent microscope) via a piezo-electrically driven glass probe, while another pipette was used for patchclamp recording of mechanically evoked currents (Fig. 5A). First, we determined activation curves for each mechanosensitive current by applying incremental mechanical forces (Fig. 5B) and found that membrane displacement evoking half of the maximum mechanical current $\left(\right.$ Stim $_{50}$ ) was $6.9 \mu \mathrm{m}$ (Fig. $5 C$ ). We then grouped currents on the basis of halfinactivation times $\left(\tau_{\text {inac }}\right)$ during $8 \mu \mathrm{m}$ displacement stimulation and revealed three classes of currents (Fig. 5D): rapidly adapting $\left(\tau_{\text {inac }}<10 \mathrm{~ms}\right)$, slowly adapting $\left(\tau_{\text {inac }}>10 \mathrm{~ms}\right.$, including intermediate and ultra-slow), and mixed adapting. The mixed adapting current was well fitted by two exponentials, instead of one exponential fitting (Drew et al., 2004): $\tau_{\text {inac } 1}<10 \mathrm{~ms}$ and $\tau_{\text {inac } 2}>10 \mathrm{~ms}$ (Fig. 5D). In other words, mixed adapting neurons are composed of both slowly and rapidly adapting mechanical currents. In contrast, some neurons did not respond to mechanical probing and were referred to as nonresponders.

For 51 recorded small-diameter $(<25$ $\mu \mathrm{m})$ Tomato $^{+}$neurons from four individual mice, corresponding to VGLUT3persistent neurons, rapidly adapting $(35.8 \pm 2.4 \%)$ and mixed adapting $(31.8 \pm 4.8 \%)$ currents are predominant, followed by slowly adapting $(7.8 \pm 2.8 \%)$ and nonresponders $(24.5 \pm 3.4 \%$ ) (Fig. 5E). For 13 recorded medium/large-diameter $(>35 \mu \mathrm{m})$ Tomato $^{+}$neurons (representing VGLUT3-transient neurons) from three individual mice, mixed adapting currents are predominant, followed by slowly adapting rapidly adapting, and nonresponders (data not shown). Thus, different subtypes of VGLUT3 lineage neurons may contain distinct mechanical channel components.

A

C ending in mutant mice.
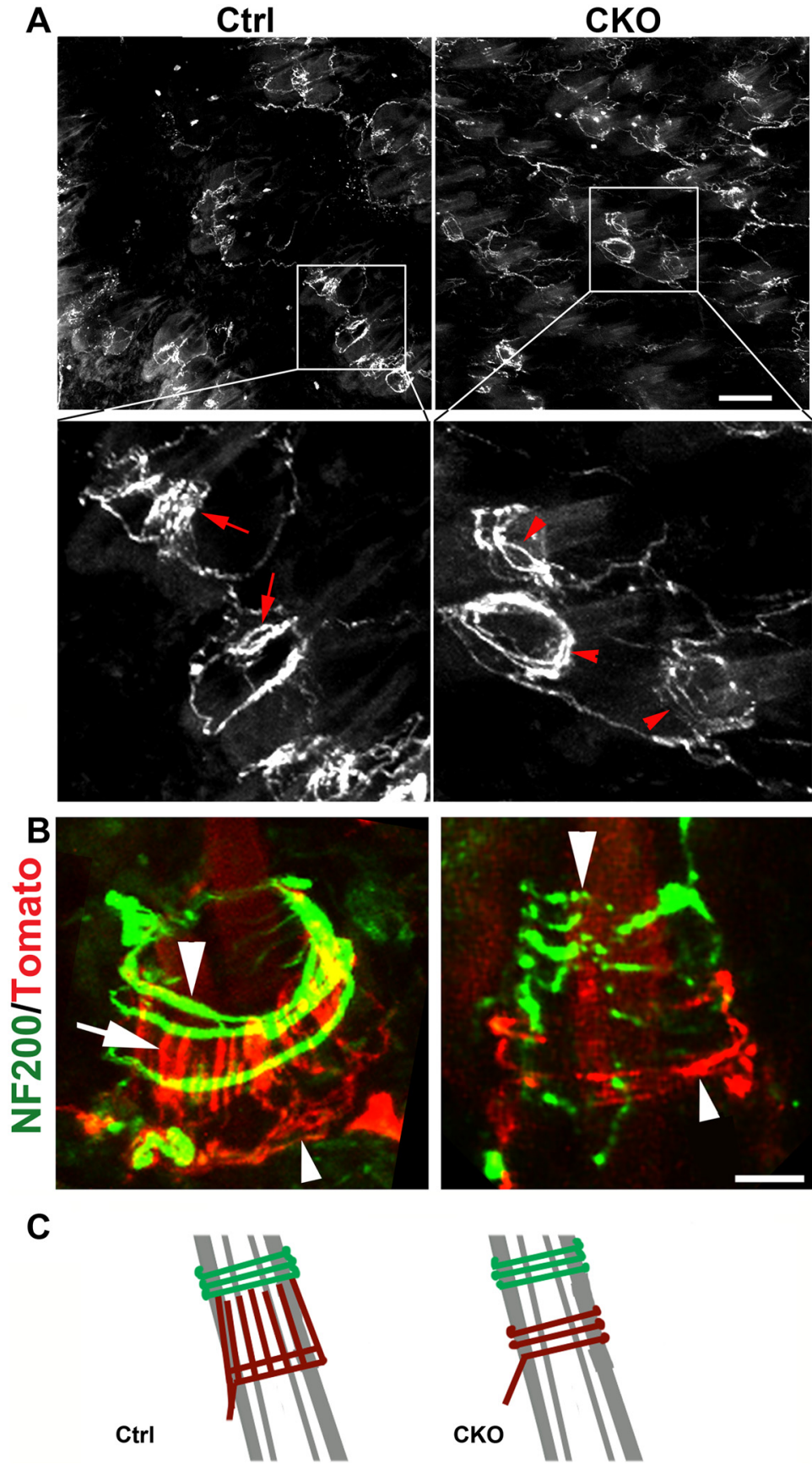

Figure 4. Runx1 controls the formation of C-LTMRs lanceolate endings. $\boldsymbol{A}$, Whole-mount view of Tomato ${ }^{+}$nerve endings innervating hair follicles in the back skin of adult ROSA ${ }^{\text {Tomato/+ }} ; V_{\text {glut }}{ }^{\text {Cre/+ }}$ control (Ctrl), and Runx $1^{\mathrm{F} / \mathrm{F}} ; \mathrm{ROSA}^{\text {Tomato/+ }} ; \mathrm{Vglut}^{\mathrm{Cre} /+}$ mutant (CKO) mice. Arrows indicating longitudinal lanceolate endings and arrowheads for circumferential endings. $B, A$ double staining of Tomato and NF200 on transverse skin sections. Arrowheads indicating NF200 ${ }^{+}$circumferential endings. Arrow in the left panel indicates lanceolate endings in wild-type control mice, while arrowheads in the right panel indicate a Tomato ${ }^{+}$ circumferential ending in mutant mice. C, Schematic diagrams illustrating the change from the lanceolate to the circumferential
We next asked whether mechanosensitivity was affected in Runxl conditional knock-outs. Recording from 55 cultured smalldiameter $(<25 \mu \mathrm{m})$ Tomato $^{+}$neurons from five individual Run $x 1^{\text {F/F }} ;$ ROSA $^{\text {Tomato/+ }} ;$ Vglut $3^{\text {Cre/+ }}$ mutant mice showed a marked loss of mechanosensitive neurons in comparison with $\mathrm{ROSA}^{\text {Tomato/+ }}$; $\mathrm{Vglut}^{\mathrm{Cre} /+}$ control mice, with rapidly adapting neurons reduced from $35.8 \pm 2.4 \%$ to $7.7 \pm 5.6 \%$, and mixed adapting neurons reduced from $31.8 \pm 4.8 \%$ to $2.0 \pm 2.0 \%$ (Fig. $5 E)$. Because of the rarity of neurons expressing slowly adapt- 
A

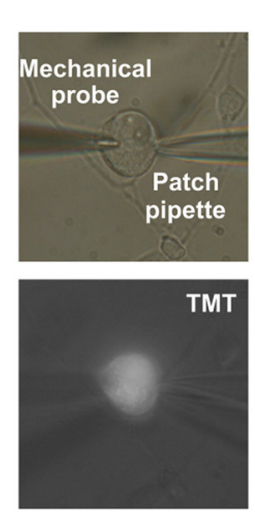

B

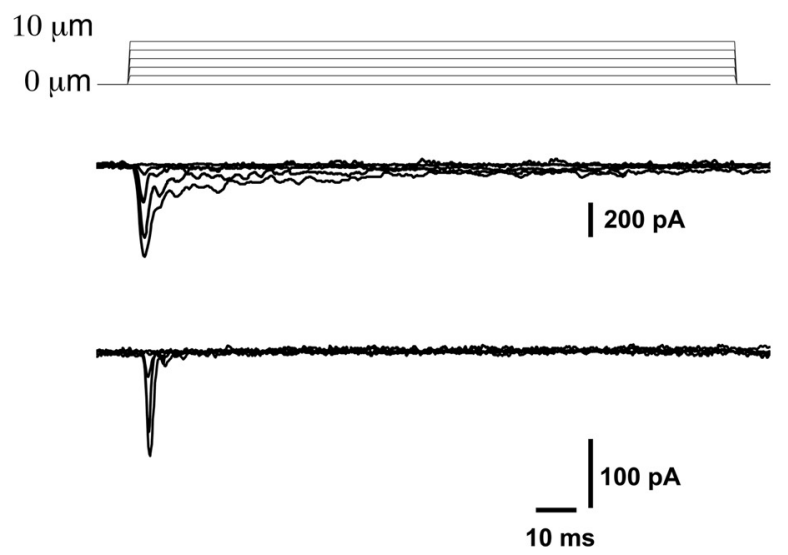

C

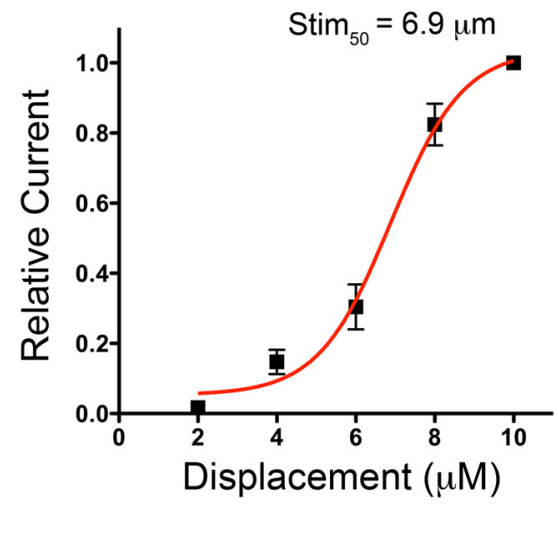

D

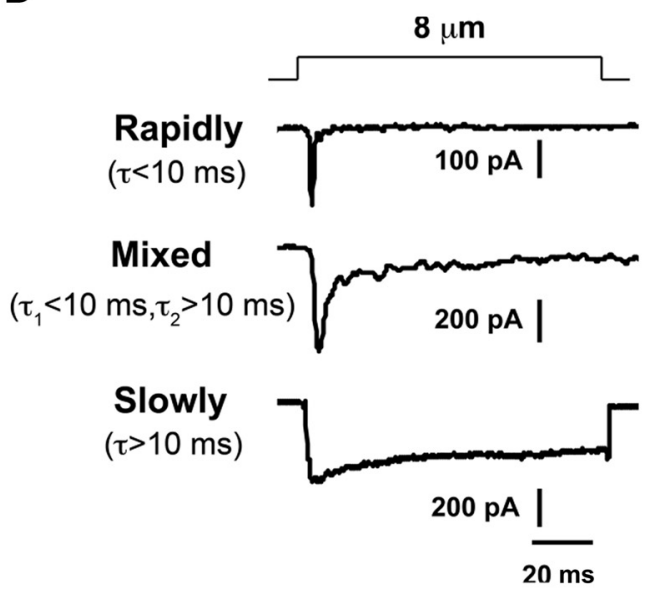

E

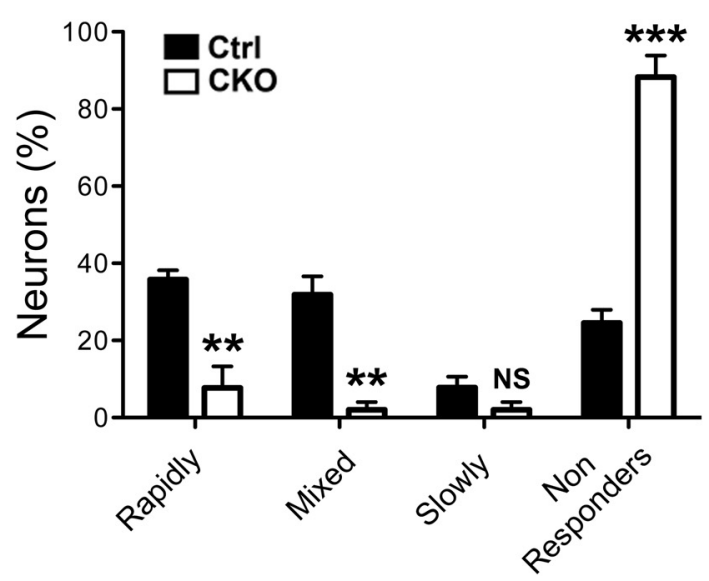

Figure 5. Runx1 controls mechanosensitivity in VGLUT3 ${ }^{+}$C-LTMRs. $A$, photograph showing mechanical stimulation of a patch-clamped Tomato ${ }^{+}$DRG neuron from ROSA ${ }^{\text {Tomato/ }+}$; Vglut $3^{\text {Cre/ }+}$ control (Ctrl) mice. B, Families of rapidly adapting mechanosensitive current traces evoked by a series of mechanical steps in $2 \mu \mathrm{m}$ increments for the DRG cells from Ctrl mice. $\boldsymbol{C}$, Relationship between stimulation displacement and relative currents from $\boldsymbol{B}(n=6)$. $\boldsymbol{D}$, Representative traces of rapidly adapting, mixed adapting, and slowly adapting currents evoked by a short mechanical stimulus of $8 \mu \mathrm{m} . \boldsymbol{E}$, Histograms showing the proportions of distinct mechanosensitive currents observed in small-diameter VGLUT3 neurons from control "Ctrl" ( $n=4$ mice, 51 neurons totally) and Runx $1^{\mathrm{F} / \mathrm{F}} ;$ ROSA ${ }^{\text {Tomato/+ }} ;$ Vglut $3^{\text {Cre/+ }}$ mutant (CKO) mice ( $n=5$ mice, 55 neurons totally), respectively. ${ }^{* *} p<0.01,{ }^{* * *} p<0.001$. Ctrl versus CKO, Student's unpaired $t$ test. NS, Nonsignificant.

ing currents, it remains uncertain whether these neurons were significantly reduced (Fig. 5E). Accordingly, there was a marked increase in nonresponders, from $24.5 \pm 3.4 \%$ in control mice to $88.3 \pm 5.6 \%$ in mutants (Fig. $5 E$ ). Moreover, the average current density in the remaining 7 (out of 55) mechanosensitive small Tomato ${ }^{+}$neurons was significantly reduced in comparison with that in control mice (from $31.8 \pm 5.3$ $\mathrm{pA} / \mathrm{pF}$ to $12.8 \pm 4.2 \mathrm{pA} / \mathrm{pF}, p<0.01)$. In contrast, no change in average current density was detected in medium/large $(>35$ $\mu \mathrm{m})$ Tomato $^{+}$neurons (data not shown), consistent with a lack of Runx1 expression in medium/large VGLUT3-transient A-mechanoreceptors. Thus, Runx1 is selectively required to establish mechanosensitivity in small-diameter VGLUT3-persistent neurons.

\section{Runx1 controls mechanosensitivity by regulating}

\section{Piezo2 expression}

Piezo2 mediates mechanically evoked currents in a subset of cultured DRG neurons in mice (Coste et al., 2010). In situ hybridization on lumbar DRG sections from ROSA $^{\text {Tomato/+ }}$; Vglut3 ${ }^{\text {Cre/+ }}$ fate-mapping mice showed that $83.7 \pm 1.9 \%$ of Tomato ${ }^{+}$neu- rons expressed Piezo2 at a relatively high level (Piezo2 ${ }^{\text {high }}$ ) (Fig. $6 A)$. Most small-diameter and medium-diameter Tomato ${ }^{+}$neurons expressed Piezo $2^{\text {high }}$ (Fig. 6A), and only large Tomato ${ }^{+}$ neurons showed Piezo ${ }^{\text {low }}$ expression (Fig. $6 \mathrm{~A}$ ).

We next examined Piezo2 expression in lumbar DRGs of Runx1 mutant and control mice. Double staining showed that the percentage of Tomato $^{+}$neurons with detectable Piezo 2 was markedly reduced in mutants (Fig. 6A), from $83.7 \pm 1.9 \%$ in

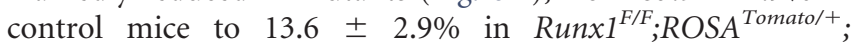
Vglut $^{\text {Cre/+ }}$ mice $(p<0.001)$. Most small-diameter Tomato ${ }^{+}$ neurons, representing VGLUT3-persistent neurons, lost Piezo2 expression (Fig. 6A). In contrast, medium-diameter Tomato ${ }^{+}$ neurons retained Piezo ${ }^{\text {high }}$ expression in mutant mice (Fig. $6 \mathrm{~A}$ ), consistent with the lack of Runxl expression in these neurons (Fig. 3A).

To determine whether Piezo2 is required to mediate mechanical responses in VGLUT3 lineage neurons, we used the same set of siRNAs (a mixture of four) used by Coste et al. (2010) to knock down Piezo2 expression in cultured DRG neurons from ROSA ${ }^{\text {Tomato/+ }}$; Vglut $3^{\text {Cre/+ }}$ mice. By solution electroporation, we found that nearly $98.3 \%$ of Tomato ${ }^{+}$neurons were trans- 
fected with siRNAs, monitored by the inclusion of a fluorescence-conjugated scrambled siRNA (data not shown). In four paired mice, compared with the re-

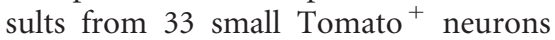
transfected with control siRNA, transfection with Piezo2 siRNAs in 38 neurons led to a marked reduction of small Tomato ${ }^{+}$ neurons expressing rapidly adapting currents (from $35.8 \pm 6.3 \%$ with control siRNA to $4.4 \pm 2.6 \%$ with Piezo 2 siRNAs), which in turn resulted in a marked increase in nonresponders (from $29.2 \pm$ $3.2 \%$ to $74.0 \pm 6.3 \%$ ) (Fig. 6 B). Piezo2 knockdown appeared to lead to a reduction of mixed adapting neurons (from $28.8 \pm 12.3 \%$ to $6.9 \pm 4.2 \%)$ and an increase of slowly adapting neurons (from $6.2 \pm 4.0 \%$ to $14.6 \pm 6.4 \%$ ), but these changes did not reach statistical significance (Fig. 6B). These findings suggest that Runx1-dependent Piezo2 is required to mediate mechanosensitivity in smalldiameter Tomato ${ }^{+}$neurons.

\section{Mechanical pain was largely unaffected} in Runx1 ${ }^{\mathrm{F} / \mathrm{F}}$; Vglut3 ${ }^{\mathrm{Cre} /+}$ mutant mice The selective impairment in C-LTMRs in Run $x 1^{\text {F/F }}$; Vglut3 $3^{\mathrm{Cre} /+}$ mutant mice offered a unique opportunity to reassess the physiological functions of these mechanoreceptors. We therefore performed a series of acute and chronic pain assays in Run $x 1^{F / F} ; V_{\text {glut3 }}{ }^{\mathrm{Cre} /+}$ mutant mice, using Runx $1^{F / F}$ or Runx $1^{F /+}$ littermates as control. The thresholds in response to light and intense mechanical stimuli delivered by Randall-Selitto apparatus and the von Frey filaments, respectively, were unchanged between mutant and control mice (Fig. 7A,B). Similarly, Run $x 1^{F / F}$; Vglut $3^{\text {Cre/+ }}$ mutant mice showed no difference in paw withdrawal latencies in response to radiation heat stimuli, in comparison with control littermates (Fig. 7C). Thus, acute mechanical and heat pain remains intact in $R u n \times 1^{F / F}$; Vglut ${ }^{\mathrm{Cre} /+}$ mutant mice.

Intradermal injection of capsaicin into the plantar of the hindpaw induces not only acute nociception but also secondary mechanical allodynia (LaMotte et al., 1991; Torebjörk et al., 1992; Campbell and Meyer, 2006). We found that duration of licking following capsaicin injections, a measurement of acute chemical pain, was comparable between $R u n x 1^{F / F} ;$ Vglut $^{\text {Cre/+ }}$ mutant mice and control littermates (Fig. 7D). Capsaicin also induced similar degrees of secondary mechanical hypersensitivity on the adjacent plantar area, as indicated by similar reduction in withdrawal thresholds in response to von Frey stimuli (Fig. 7D). Thus, capsaicininduced secondary mechanical allodynia in the glabrous skin also remained intact in mutants.

To assess neuropathic pain, we used the SNI model (Decosterd and Woolf, 2000). We found that both control and mutant mice showed indistinguishable mechanical hypersensitivity following SNI (Fig. 7E), indicating that neuropathic mechanical pain is unaffected in mutant mice.
To assess inflammatory pain, we first performed intraplantar injection of the CFA. Three day after intraplantar injection of CFA, both thermal hypersensitivity (measured by the radiant heat assay) and mechanical allodynia (measured by the von Frey assay) remained intact in $\mathrm{Runx} \times 1^{\mathrm{F} / \mathrm{F}} ; \mathrm{Vglut} 3^{\mathrm{Cre} /+}$ mice in comparison with control mice (Fig. $7 F$ ). We next performed intraplantar injection of carrageenan (Kayser and Guilbaud, 1987). Thermal hypersensitivity was again unchanged in mutant mice (Fig. $7 G$ ). However, although mechanical hypersensitivity induced by carrageenan still developed in mutants, the mutants showed a modest, yet significant, increase in mechanical thresholds, in comparison with control littermates (Fig. 7G), suggesting a minor impairment of inflammatory mechanical pain. Collectively, these studies suggest that developmental impairment of VGLUT3-persistent neurons in $R u n \times 1^{F / F}$; Vglut ${ }^{\mathrm{Cre} /+}$ mice does not markedly affect acute or chronic mechanical pain measured from the glabrous skin.

Since $\mathrm{TH}^{+}$C-LTMRs only innervate the hairy skin (Li et al., 2011), we further examined mechanical allodynia following capsaicin injection into the hairy skin of the dorsal hindpaw. We again did not find any difference between Runx $1^{F / F} ; V_{g l u t} 3^{\mathrm{Cre} /+}$ mice versus control mice (data not shown). All together, we conclude that mechanical allodynia is largely unaffected in $\operatorname{Run} x 1^{\mathrm{F} / F}$; Vglut $3^{\mathrm{Cre} /+}$ mutant mice. 

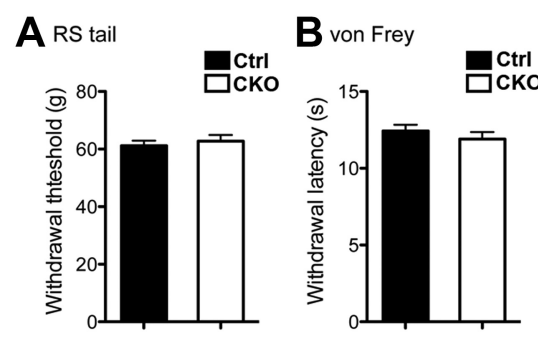

D Capsaicin
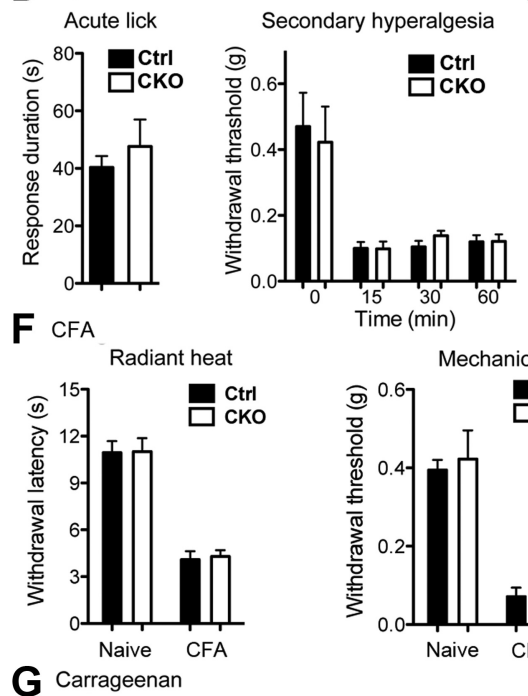

$\begin{array}{lll}15 & 30 & 60 \\ \text { Time (min) } & \\ \text { Mechanical }\end{array}$

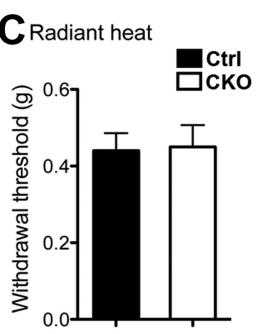

E Spared nerve injury
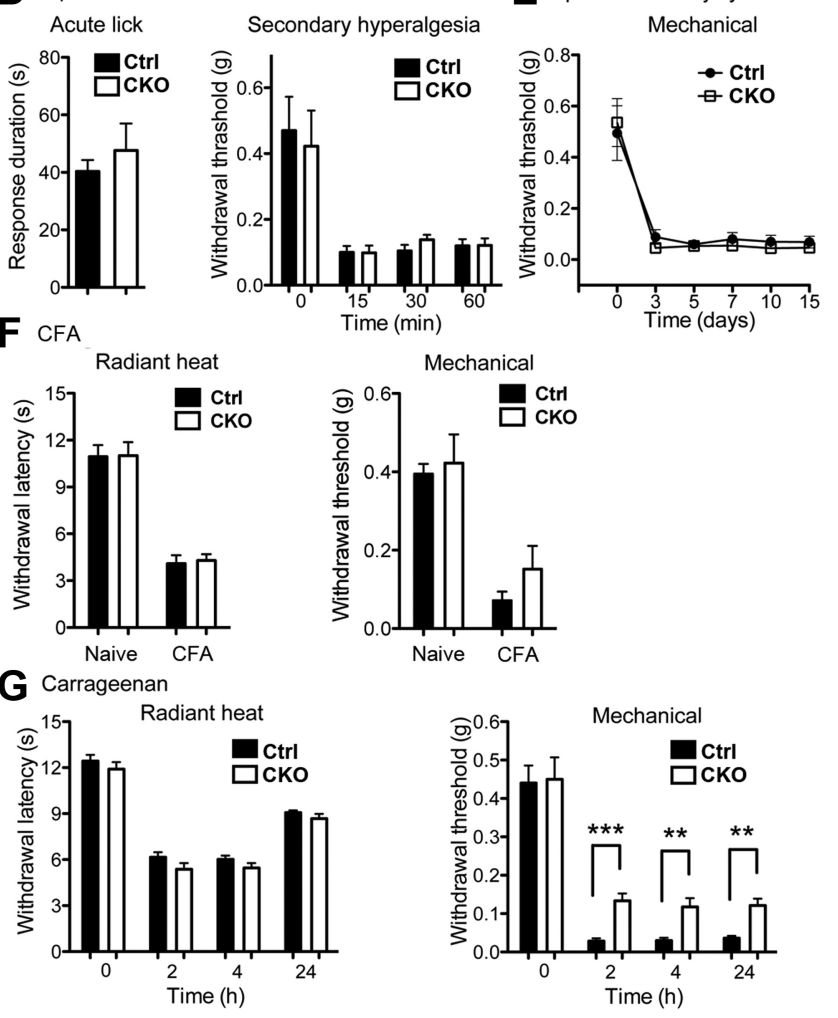

Figure 7. Pain behavioral analyses. $\boldsymbol{A}$, The Randall-Selitto assay. Runx $1^{\mathrm{F} / \mathrm{F}} ; \mathrm{Vglut} 3^{\mathrm{Cre} /+} \mathrm{mu}-$ tant (CKO) and control (Ctrl) mice showed the same thresholds to tail withdrawal ( $\mathrm{Ctrl}, n=10$, $61.2 \pm 1.8 \mathrm{~g} ;$ ( $C K 0, n=8,62.8 \pm 2.2 \mathrm{~g} ; p>0.05$, Student's unpaired $t$ test). $\boldsymbol{B}$, The von Frey assays for acute mechanical pain measurement. No difference in withdrawal thresholds (Ctrl, $n=10,0.44 \pm 0.05 \mathrm{~g} ;$ CKO $n=8,0.45 \pm 0.06 \mathrm{~g} ; p>0.05$, Student's unpaired $t$ test). $C$, The Hargreaves radiant heat test. No difference in withdrawal thresholds ( $\mathrm{Ctrl}, n=10,12.4 \pm$ $0.4 \mathrm{~s} ;$ ( CKO, $n=8,11.9 \pm 0.5 \mathrm{~s} ; p>0.05$, Student's unpaired $t$ test). $\boldsymbol{D}$, In both (trl and CKO mice, capsaicin injection into the hindpaw produced similar licking response in the first 5 min (Ctrl, $n=6,40.3 \pm 4.0 \mathrm{~s} ;$ CKO, $n=5,47.6 \pm 9.4 \mathrm{~s} ; p>0.05$, Student's unpaired $t$ test). Both CKO and Ctrl mice showed similar decrease in mechanical threshold at a distance from the injection site at 15, 30, and 60 min after injection (Ctrl, $n=7 ;$ CKO, $n=7 ; p>0.05$, one-way ANOVA). $E$, SNI-induced neuropathic pain. After $S \mathrm{NI}$, a similar reduction in mechanical thresholds by von Frey assay was observed in Ctrl versus CKO mice (Ctrl, $n=7 ;$ CKO, $n=10 ; p>0.05$, by one-way ANOVA). F, CFA-induced inflammatory pain. Both Ctrl and CKO mice were injected with CFA in one hindpaw. Tested at before (naive) and $3 \mathrm{~d}$ after (CFA) injection (Ctrl, $n=7$; CKO, $n=8 ; p>0.05$, Student's unpaired $t$ test). $\mathbf{G}$, Carrageenan-induced inflammatory pain. Ctrl and CKO mice were injected with carrageenan in the hindpaw. Tested at 2, 4, and $24 \mathrm{~h}$ after injection. Both genotypes show a similar withdrawal threshold to radiant heat at all times tested (Ctrl, $n=10 ;$ CKO, $n=8 ; p>0.05$, Student's unpaired $t$ test). CK0 mice exhibited a small but significant increase in mechanical threshold at all times tested in comparison with Ctrl mice (Ctrl, $n=10$; CKO, $n=8 ;{ }^{* *} p<0.01 ;{ }^{* * *} p<0.001$; Ctrl vs CKO, Student's unpaired $t$ test).

\section{Discussion}

By investigating the ontogeny, mechanosensitivity, developmental control, and physiological functions of VGLUT3 lineage sensory neurons, we have gained novel insight into several areas on mammalian mechanoreceptors. First, the genetic fate mapping shows that VGLUT3 lineage mechanoreceptors are composed of multiple subgroups, including (1) medium/large VGLUT3transient myelinated A-mechanoreceptors forming the Merkel cell-neurite complex, and (2) small-diameter VGLUT3-persistent unmyelinated neurons that are further divided into two subpopulations: $\mathrm{TH}^{+}$C-LTMRs forming the lanceolate endings around hairs and $\mathrm{TH}^{-}$neurons forming epidermal-free nerve endings. Second, with great excitement generated from the recent identification of Piezo2 as a mechanically gated ion channel, we now show that Piezo2 is expressed in VGLUT3 lineage C-LTMRs, and Piezo 2 mediates mechanosensitivity in these neurons. Third, the runt domain transcription factor Runx1 plays a pivotal role in controlling C-LTMR development, including the formation of terminal morphologies, the expression of VGLUT3 and Piezo2, and the establishment of mechanosensitivity. Fourth, with selective loss of VGLUT3 and mechanosensitivity in C-LTMRs, behavioral analyses in this new line of Runx1 conditional knockouts allow us to revisit the roles of these neurons in sensing mechanical pain.

\section{Distinct transcription factors control the formation of specialized mechanoreceptor terminal nerve endings}

Most known low threshold mechanoreceptors form specialized nerve endings that allow them to respond to specific types of mechanical stimuli (Johnson, 2001; Bautista and Lumpkin, 2011; Delmas et al., 2011). Our studies consolidate the idea that distinct transcription factors control the formation of these nerve endings. The basic leucine-zipper transcription factor c-Maf and the ets domain protein Er81 are required for the formation of the Pacinian corpuscles that are specialized to sense high-frequency vibrations (Sedý et al., 2006; Hu et al., 2012; Wende et al., 2012). Both c-Maf and the homeobox protein Shox2 are necessary for the formation of the Meissner corpuscles that respond to skin motions and detect low-frequency vibration (Abdo et al., 2011; Scott et al., 2011; Wende et al., 2012). In the hairy skin, the longitudinal lanceolate endings respond to hair defection, and two recent studies reveal heterogeneity of mechanoreceptors forming these endings (Li et al., 2011; Wende et al., 2012). Formation of $\mathrm{NF} 200^{+}$myelinated lanceolate endings is dependent on c-Maf (Wende et al., 2012). We demonstrate here that Runxl is required for the $\mathrm{TH}^{+}$subset of C-LTMRs to form unmyelinated lanceolate endings. In the absence of Runx1, prospective unmyelinated lanceolate endings are either lost or transformed to become circumferential endings. The Merkel cell-neurite complex is specialized for fine tactile discrimination, thereby the perception of form and texture (Johnson, 2001; Bautista and Lumpkin, 2011; Delmas et al., 2011). The basic helix-loop-helix protein Atoh1 controls the genesis of the Merkel cells (Maricich et al., 2009, 2012). Among mechanoreceptors innervating the Merkel cells, Shox2 and the Runx1-related protein Runx3 appear to be required for proper development of the $\operatorname{TrkB}^{+}$and $\operatorname{TrkC}^{+}$subsets, respectively (Senzaki et al., 2010; Abdo et al., 2011). We show here that VGLUT3-transient myelinated mechanoreceptors innervate the Merkel cells, and we further found that among them $55 \%$ and $45 \%$ express the neurotrophin receptors TrkB and TrkC, respectively (data not shown). Further studies will be warranted to determine whether Runx3 and Shox 2 specify distinct subsets of VGLUT3-transient A-mechanoreceptor. Altogether, the emerging theme is that distinct transcription factors act alone or in combination to control the formation of distinct mechanoreceptor nerve endings and/or end organs. 


\section{Runx1-dependent Piezo2 mediates mechanosensitivity in C-LTMRs}

Piezo proteins have been shown to be the long sought mechanically gated ion channels in mammals and in flies (Coste et al., 2010, 2012; Kim et al., 2012), a channel that is distinct from those found in C. elegans (Geffeney and Goodman, 2012). In mice, elevated Piezo2 (Piezo2 ${ }^{\text {high }}$ ) expression is detected in $\sim 20 \%$ of DRG neurons (Coste et al., 2010). Here, we found that a large subset of Piezo ${ }^{\text {high }}$ neurons represent VGLUT3 lineage neurons, including small-diameter VGLUT3-persistent neurons and medium-diameter A-mechanoreceptors. Knockdown of Piezo2 leads to a marked loss of rapidly adapting mechanical current in small VGLUT3-persistent neurons, and a concurrent increase of mechano-insensitive neurons (Fig. 6). The loss of Piezo2 expression should at least partly contribute to the marked loss of mechanosensitivity in VGLUT3-persistent neurons of Runx1 mutants, although our data do not rule out that Runx1 may control other molecular components involved with mechanotransduction.

Notably, the adaption rates of mechanically evoked currents recorded from cultured neurons are different from those recorded from ex vivo skin-nerve preparations. By ex vivo skinnerve preparations, C-LTMR neurons exhibit intermediate adaption rates in response to stationary mechanical stimuli (Seal et al., 2009; Li et al., 2011), and Merkel cells are innervated by type I slowly adapting $\mathrm{A} \beta$-LTMRs, or SA $1 \mathrm{~A} \beta$-fibers (Lumpkin et al., 2010; Bautista and Lumpkin, 2011; Delmas et al., 2011). In contrast, mechanically evoked currents from cultured VGLUT3 lineage neurons mainly exhibit rapid or mixed adaption rates. The simplest interpretation is that adaption rates are modulated by specialized nerve endings/structures or the extracellular matrix molecules in the skin (Lumpkin et al., 2010). For example, laminin-332 released from keratinocytes is able to suppress the rapidly adapting mechanosensitive current (Chiang et al., 2011). Similarly, Merkel cells themselves are mechanosensitive, and the SA1 current is selectively lost in mice lacking Merkel cells, despite the continuous innervation of $\mathrm{A} \beta$-fibers to prospective touch domes (Maricich et al., 2009).

\section{What are the physiological functions of VGLUT3-persistent DRG neurons?}

Seal et al. (2009) reported that mechanical allodynia induced by inflammation, capsaicin, or nerve injury was all markedly impaired in mice lacking Vglut3. They further proposed that VGLUT3-persistent C-LTMRs are required for the execution, but not the induction, of mechanical allodynia (Seal et al., 2009). This interpretation is, however, complicated by the VGLUT3 expression in many parts of the nervous system (El Mestikawy et al., 2011) (Fig. 3). By using Vglut3-Cre mice to knock out Runx1, we have now created a new line of mutant mice $\left(R u n x 1^{F / F}\right.$; Vglut $3^{\mathrm{Cre} /+}$ ) with a selective loss of VGLUT3 and mechanosensitivity in VGLUT3-persistent neurons, which offered a unique opportunity to reassess the physiological functions of these neurons.

We found that Runx1-dependent VGLUT3-persistent neurons do modestly contribute to the inflammatory mechanical hypersensitivity induced by carrageenan and measured from the hindpaw plantar. Among VGLUT3-persistent neurons, the $\mathrm{TH}^{+}$ C-LTMRs innervates the hairy skin (Li et al., 2011), and only the $\mathrm{TH}^{-}$subset innervates the thick glabrous skin, forming the D.P.E endings that pass through the dermal papillae to enter the epidermis. Previous electrophysiological recording showed that most if, not all, VGLUT3-persistent neurons are C-LTMRs (Li et al.,
2011). Thus, the $\mathrm{TH}^{-}$subset of VGLUT3-persistent neurons might also function as C-LTMRs, although further studies are needed to consolidate this hypothesis. Regardless, a defect in $\mathrm{TH}^{-}$neurons could in principle contribute to the minor inflammatory pain deficit measured from the glabrous skin in Run $x 1^{F / F}$; Vglut3 ${ }^{\text {Cre/+ }}$ knock-out mice.

Surprisingly, mechanical allodynia induced by nerve lesions, capsaicin, and another inflammatory reagent CFA in $R u n x 1^{F / F}$; Vglut $3^{\mathrm{Cre} /+}$ knock-out mice is unaffected in $R u n \times 1^{F / F}$; Vglut $3^{\mathrm{Cre} /+}$ knock-out mice. Even carrageenan-induced mechanical pain is only modestly impaired. How could we explain the marked loss of this type of pain in Vglut3 complete null mice? Two possibilities are worthy for consideration.

First, VGLUT3 may only play a developmental role in VGLUT3-persistent neurons. VGLUT3 expression was initiated at prenatal and neonatal stages (Fig. 1). In Runx $1^{F / F} ; V_{g l u t 3}{ }^{\mathrm{Cre} /+}$ knock-out mice, a transient VGLUT3 expression was still preserved at neonatal stages since Vglut3-Cre mice were used for Runx1 knock-out. Transient VGLUT3 expression has been shown to play a role in circuit maturation in the brain (Noh et al., 2010), and it is well known that spinal circuits also undergo maturation processes during postnatal development (Fitzgerald, 2005). Thus, if VGLUT3-dependent glutamate release from VGLUT3-persistent DRG neurons plays a role in circuit maturation and if this process only requires a transient VGLUT3 expression, maturation of sensory circuits would be impaired in Vglut3-null mice, but not in Runx $1^{F / F}$; Vglut $3^{\mathrm{Cre} /+}$ knock-out mice.

Second, VGLUT3 activity in other parts of the nervous system may control mechanical hypersensitivity, such as neurons forming the Merkel cell-neurite complex, neurons located in the dorsal spinal cord, and hindbrain 5-HT neurons. Accordingly, the normal VGLUT3 expression in these neural cells in $R u n x 1^{F / F}$; Vglut $3^{\mathrm{Cre} /+}$ knock-out mice might explain why mechanical pain is unaffected. This interpretation is consistent with reports that VGLUT3 expression is confined to Nav1.8 lineage DRG neurons, and neuropathic mechanical pain is unaffected upon ablation of these neurons (Abrahamsen et al., 2008; Shields et al., 2012). Future conditional knock-out of VGLUT3 in various parts of the nervous system will be needed to clarify where VGLUT3 operates to mediate mechanical pain.

\section{References}

Abdo H, Li L, Lallemend F, Bachy I, Xu XJ, Rice FL, Ernfors P (2011) Dependence on the transcription factor Shox 2 for specification of sensory neurons conveying discriminative touch. Eur J Neurosci 34: 1529-1541. CrossRef Medline

Abrahamsen B, Zhao J, Asante CO, Cendan CM, Marsh S, MartinezBarbera JP, Nassar MA, Dickenson AH, Wood JN (2008) The cell and molecular basis of mechanical, cold, and inflammatory pain. Science 321:702-705. CrossRef Medline

Arber S, Ladle DR, Lin JH, Frank E, Jessell TM (2000) ETS gene Er81 controls the formation of functional connections between group Ia sensory afferents and motor neurons. Cell 101:485-498. CrossRef Medline

Bautista DM, Lumpkin EA (2011) Perspectives on: information and coding in mammalian sensory physiology: probing mammalian touch transduction. J Gen Physiol 138:291-301. CrossRef Medline

Björnsdotter M, Morrison I, Olausson H (2010) Feeling good: on the role of C fiber mediated touch in interoception. Exp Brain Res 207:149-155. CrossRef Medline

Campbell JN, Meyer RA (2006) Mechanisms of neuropathic pain. Neuron 52:77-92. CrossRef Medline

Chaplan SR, Bach FW, Pogrel JW, Chung JM, Yaksh TL (1994) Quantitative assessment of tactile allodynia in the rat paw. J Neurosci Methods 53:55-63. CrossRef Medline 
Chen CL, Broom DC, Liu Y, de Nooij JC, Li Z, Cen C, Samad OA, Jessell TM, Woolf CJ, Ma Q (2006) Runx1 determines nociceptive sensory neuron phenotype and is required for thermal and neuropathic pain. Neuron 49:365-377. CrossRef Medline

Chiang LY, Poole K, Oliveira BE, Duarte N, Sierra YA, Bruckner-Tuderman L, Koch M, Hu J, Lewin GR (2011) Laminin-332 coordinates mechanotransduction and growth cone bifurcation in sensory neurons. Nat Neurosci 14:993-1000. CrossRef Medline

Corey DP, Hudspeth AJ (1980) Mechanical stimulation and micromanipulation with piezoelectric bimorph elements. J Neurosci Methods 3:183202. CrossRef Medline

Coste B, Mathur J, Schmidt M, Earley TJ, Ranade S, Petrus MJ, Dubin AE, Patapoutian A (2010) Piezol and Piezo2 are essential components of distinct mechanically activated cation channels. Science 330:55-60. CrossRef Medline

Coste B, Xiao B, Santos JS, Syeda R, Grandl J, Spencer KS, Kim SE, Schmidt M, Mathur J, Dubin AE, Montal M, Patapoutian A (2012) Piezo proteins are pore-forming subunits of mechanically activated channels. Nature 483:176-181. CrossRef Medline

Decosterd I, Woolf CJ (2000) Spared nerve injury: an animal model of persistent peripheral neuropathic pain Pain 87:149-158. CrossRef

Delmas P, Hao J, Rodat-Despoix L (2011) Molecular mechanisms of mechanotransduction in mammalian sensory neurons. Nat Rev Neurosci 12:139-153. CrossRef Medline

Drew LJ, Wood JN, Cesare P (2002) Distinct mechanosensitive properties of capsaicin-sensitive and -insensitive sensory neurons. J Neurosci 22:RC228. Medline

Drew LJ, Rohrer DK, Price MP, Blaver KE, Cockayne DA, Cesare P, Wood JN (2004) Acid-sensing ion channels ASIC2 and ASIC3 do not contribute to mechanically activated currents in mammalian sensory neurones. J Physiol 556:691-710. CrossRef Medline

El Mestikawy S, Wallén-Mackenzie A, Fortin GM, Descarries L, Trudeau LE (2011) From glutamate co-release to vesicular synergy: vesicular glutamate transporters. Nat Rev Neurosci 12:204-216. CrossRef Medline

Fitzgerald M (2005) The development of nociceptive circuits. Nat Rev Neurosci 6:507-520. CrossRef Medline

Fremeau RT Jr, Voglmaier S, Seal RP, Edwards RH (2004) VGLUTs define subsets of excitatory neurons and suggest novel roles for glutamate. Trends Neurosci 27:98-103. CrossRef Medline

Geffeney SL, Goodman MB (2012) How we feel: ion channel partnerships that detect mechanical inputs and give rise to touch and pain perception. Neuron 74:609-619. CrossRef Medline

Growney JD, Shigematsu H, Li Z, Lee BH, Adelsperger J, Rowan R, Curley DP, Kutok JL, Akashi K, Williams IR, Speck NA, Gilliland DG (2005) Loss of Runxl perturbs adult hematopoiesis and is associated with a myeloproliferative phenotype. Blood 106:494-504. CrossRef Medline

Haeberle H, Fujiwara M, Chuang J, Medina MM, Panditrao MV, Bechstedt S, Howard J, Lumpkin EA (2004) Molecular profiling reveals synaptic release machinery in Merkel cells. Proc Natl Acad Sci U S A 101:1450314508. CrossRef Medline

Hao J, Delmas P (2011) Recording of mechanosensitive currents using piezoelectrically driven mechanostimulator. Nat Protoc 6:979-990. CrossRef Medline

Hargreaves K, Dubner R, Brown F, Flores C, Joris J (1988) A new and sensitive method for measuring thermal nociception in cutaneous hyperalgesia. Pain 32:77-88. CrossRef Medline

Hu J, Lewin GR (2006) Mechanosensitive currents in the neurites of cultured mouse sensory neurones. J Physiol 577:815-828. CrossRef Medline

Hu J, Huang T, Li T, Guo Z, Cheng L (2012) c-Maf is required for the development of dorsal horn laminae III/IV neurons and mechanoreceptive DRG axon projections. J Neurosci 32:5362-5373. CrossRef Medline

Inoue K, Ozaki S, Shiga T, Ito K, Masuda T, Okado N, Iseda T, Kawaguchi S, Ogawa M, Bae SC, Yamashita N, Itohara S, Kudo N, Ito Y (2002) Runx3 controls the axonal projection of proprioceptive dorsal root ganglion neurons. Nat Neurosci 5:946-954. CrossRef Medline

Johnson KO (2001) The roles and functions of cutaneous mechanoreceptors. Curr Opin Neurobiol 11:455-461. CrossRef Medline

Kayser V, Guilbaud G (1987) Local and remote modifications of nociceptive sensitivity during carrageenin-induced inflammation in the rat. Pain 28 : 99-107. CrossRef Medline

Kim SE, Coste B, Chadha A, Cook B, Patapoutian A (2012) The role of
Drosophila Piezo in mechanical nociception. Nature 483:209-212. CrossRef Medline

Kramer I, Sigrist M, de Nooij JC, Taniuchi I, Jessell TM, Arber S (2006) A role for Runx transcription factor signaling in dorsal root ganglion sensory neuron diversification. Neuron 49:379-393. CrossRef Medline

Kucera J, Cooney W, Que A, Szeder V, Stancz-Szeder H, Walro J (2002) Formation of supernumerary muscle spindles at the expense of Golgi tendon organs in ER81-deficient mice. Dev Dyn 223:389-401. CrossRef Medline

Lallemend F, Ernfors P (2012) Molecular interactions underlying the specification of sensory neurons. Trends Neurosci 35:373-381. CrossRef Medline

LaMotte RH, Shain CN, Simone DA, Tsai EF (1991) Neurogenic hyperalgesia: psychophysical studies of underlying mechanisms. J Neurophysiol 66:190-211. Medline

Levanon D, Bettoun D, Harris-Cerruti C, Woolf E, Negreanu V, Eilam R, Bernstein Y, Goldenberg D, Xiao C, Fliegauf M, Kremer E, Otto F, Brenner O, Lev-Tov A, Groner Y (2002) The Runx3 transcription factor regulates development and survival of TrkC dorsal root ganglia neurons. EMBO J 21:3454-3463. CrossRef Medline

Li L, Rutlin M, Abraira VE, Cassidy C, Kus L, Gong S, Jankowski MP, Luo W, Heintz N, Koerber HR, Woodbury CJ, Ginty DD (2011) The functional organization of cutaneous low-threshold mechanosensory neurons. Cell 147:1615-1627. CrossRef Medline

Liu Y, Ma Q (2011) Generation of somatic sensory neuron diversity and implications on sensory coding. Curr Opin Neurobiol 21:52-60. CrossRef Medline

Liu Y, Abdel Samad O, Zhang L, Duan B, Tong Q, Lopes C, Ji RR, Lowell BB, Ma Q (2010) VGLUT2-dependent glutamate release from peripheral nociceptors is required to sense pain and suppress itch. Neuron 68:543-556. CrossRef Medline

Löken LS, Wessberg J, Morrison I, McGlone F, Olausson H (2009) Coding of pleasant touch by unmyelinated afferents in humans. Nat Neurosci 12:547-548. CrossRef Medline

Lumpkin EA, Marshall KL, Nelson AM (2010) The cell biology of touch. J Cell Biol 191:237-248. CrossRef Medline

Madisen L, Zwingman TA, Sunkin SM, Oh SW, Zariwala HA, Gu H, Ng LL, Palmiter RD, Hawrylycz MJ, Jones AR, Lein ES, Zeng H (2010) A robust and high-throughput Cre reporting and characterization system for the whole mouse brain. Nat Neurosci 13:133-140. CrossRef Medline

Maricich SM, Wellnitz SA, Nelson AM, Lesniak DR, Gerling GJ, Lumpkin EA, Zoghbi HY (2009) Merkel cells are essential for light-touch responses. Science 324:1580-1582. CrossRef Medline

Maricich SM, Morrison KM, Mathes EL, Brewer BM (2012) Rodents rely on Merkel cells for texture discrimination tasks. J Neurosci 32:32963300. CrossRef Medline

Marmigère F, Montelius A, Wegner M, Groner Y, Reichardt LF, Ernfors P (2006) The Runx1/AML1 transcription factor selectively regulates development and survival of TrkA nociceptive sensory neurons. Nat Neurosci 9:180-187. CrossRef Medline

McCarter GC, Reichling DB, Levine JD (1999) Mechanical transduction by rat dorsal root ganglion neurons in vitro. Neurosci Lett 273:179-182. CrossRef Medline

Noh J, Seal RP, Garver JA, Edwards RH, Kandler K (2010) Glutamate corelease at GABA/glycinergic synapses is crucial for the refinement of an inhibitory map. Nat Neurosci 13:232-238. CrossRef Medline

Nunzi MG, Pisarek A, Mugnaini E (2004) Merkel cells, corpuscular nerve endings and free nerve endings in the mouse palatine mucosa express three subtypes of vesicular glutamate transporters. J Neurocytol 33:359-376. CrossRef Medline

Olausson H, Wessberg J, Morrison I, McGlone F, Vallbo A (2010) The neurophysiology of unmyelinated tactile afferents. Neurosci Biobehav Rev 34:185-191. CrossRef Medline

Scott A, Hasegawa H, Sakurai K, Yaron A, Cobb J, Wang F (2011) Transcription factor short stature homeobox 2 is required for proper development of tropomyosin-related kinase B-expressing mechanosensory neurons. J Neurosci 31:6741-6749. CrossRef Medline

Seal RP, Wang X, Guan Y, Raja SN, Woodbury CJ, Basbaum AI, Edwards RH (2009) Injury-induced mechanical hypersensitivity requires C-low threshold mechanoreceptors. Nature 462:651-655. CrossRef Medline

Sedý J, Tseng S, Walro JM, Grim M, Kucera J (2006) ETS transcription factor ER81 is required for the Pacinian corpuscle development. Dev Dyn 235:1081-1089. CrossRef Medline 
Senzaki K, Ozaki S, Yoshikawa M, Ito Y, Shiga T (2010) Runx3 is required for the specification of TrkC-expressing mechanoreceptive trigeminal ganglion neurons. Mol Cell Neurosci 43:296-307. CrossRef Medline

Shields SD, Ahn HS, Yang Y, Han C, Seal RP, Wood JN, Waxman SG, DibHajj SD (2012) $\mathrm{Na}(\mathrm{v}) 1.8$ expression is not restricted to nociceptors in mouse peripheral nervous system. Pain 153:2017-2030. CrossRef Medline

Theriault FM, Nuthall HN, Dong Z, Lo R, Barnabe-Heider F, Miller FD, Stifani S (2005) Role for Runx1 in the proliferation and neuronal differentiation of selected progenitor cells in the mammalian nervous system. J Neurosci 25:2050-2061. CrossRef Medline

Torebjörk HE, Lundberg LE, LaMotte RH (1992) Central changes in processing of mechanoreceptive input in capsaicin-induced secondary hyperalgesia in humans. J Physiol 448:765-780. Medline

Vilceanu D, Stucky CL (2010) TRPA1 mediates mechanical currents in the plasma membrane of mouse sensory neurons. PLoS One 5:e12177. CrossRef Medline

Wende H, Lechner SG, Cheret C, Bourane S, Kolanczyk ME, Pattyn A, Reuter K, Munier FL, Carroll P, Lewin GR, Birchmeier C (2012) The transcription factor c-Maf controls touch receptor development and function. Science 335:1373-1376. CrossRef Medline

Yoshikawa M, Senzaki K, Yokomizo T, Takahashi S, Ozaki S, Shiga T (2007) Runx1 selectively regulates cell fate specification and axonal projections of dorsal root ganglion neurons. Dev Biol 303:663-674. CrossRef Medline

Zagami CJ, Stifani S (2010) Molecular characterization of the mouse superior lateral parabrachial nucleus through expression of the transcription factor Runx1. PLoS One 5:e13944. CrossRef Medline

Zotterman Y (1939) Touch, pain and tickling: an electro-physiological investigation on cutaneous sensory nerves. J Physiol 95:1-28. Medline 